\title{
A two-zone model for natural cross-ventilation
}

\author{
G. Carrilho da Graça ${ }^{\text {a, b, * , N.C. Daish }}{ }^{\text {a }}$, P.F. Linden ${ }^{\text {a, c }}$ \\ ${ }^{a}$ Dept. of Mechanical and Aerospace Engineering, University of California, San Diego, USA \\ ${ }^{\mathrm{b}}$ Universidade de Lisboa, Faculdade de Ciências, D.E.G.G.E., Portugal \\ ${ }^{c}$ Dept. of Applied Mathematics and Theoretical Physics, Centre for Mathematical Sciences, Univ. of Cambridge, United Kingdom
}

\section{A R T I C L E I N F O}

\section{Article history:}

Received 2 January 2015

Received in revised form

10 February 2015

Accepted 13 February 2015

Available online 24 February 2015

\section{Keywords:}

Cross-ventilation

Natural-ventilation

CFD

Simplified model

\begin{abstract}
A B S T R A C T
Cross-ventilation flows (CV) are characterized by significant inflow momentum conservation as fluid flows across an enclosed rectangular volume as a confined jet. When the inflow area is smaller than the volume cross-sectional area the CV flow has distinct jet and recirculation flow regions. The simplified model presented in this paper characterizes the $\mathrm{CV}$ flow as the result of a confined axisymmetric jet driving one or two recirculation regions, each of which is a lid-driven cavity flow. The model consists of calibrated analytical scaling laws that predict characteristic velocities in the jet and recirculation flow regions using as inputs the inflow velocity, and relevant geometry parameters. The proposed model can deal with impinging flow angle effects and multiple inflow opening configurations. Comparison between the model predictions and validated computational fluid dynamics (CFD) simulations show adequate agreement for simplified prediction of characteristic flow velocities in cross-ventilated spaces.
\end{abstract}

() 2015 Elsevier Ltd. All rights reserved.

\section{Introduction}

Cross-ventilation flows (CV) are characterized by significant inflow momentum conservation as fluid flows across an enclosed space as a confined jet. Depending on the enclosing volume and inflow geometry the flow can be two or three-dimensional. Initial work on simplified analytical modelling of turbulent confined jets compared experimental studies with simplified solutions of the mass and momentum conservation equations for application in industrial furnace optimization [1,2]. In these cases a jet flows into a co-flowing stream with variable velocity. When the co-flow velocity is low the flow field displays recirculation regions surrounding the inflow jet. Fig. 1 shows a laser-induced fluorescence flow visualization of a water model used to study oscillations in a two-dimensional CV flow [3]. In this figure the two components of a typical CV flow are clearly visible: the confined jet, which is the dark region in the centre of the image, and the recirculation regions on either side of the jet.

In addition to industrial applications, CV flows can be found in fields such as medicine and building natural ventilation. In the medical area, simplified modelling of CV is used to predict orifice

\footnotetext{
* Corresponding author. Universidade de Lisboa, Faculdade de Ciências, D.E.G.G.E., Portugal. Tel.: +351 914310067.

E-mail address: gcg@fc.ul.pt (G. Carrilho da Graça).
}

size in cardiovalvular regurgitation from average jet velocity in the heart cavities [4]. In building natural ventilation, CV flows occur as the air flows through façade openings, across rooms, as an approximately axisymmetric jet [5,6]. A typical CV configuration is sketched in Fig. 1, in which an external wind $U$ impinges on a building containing a rectangular space of width $W$, height $H$ and depth $D$ with an opening of area $A_{\text {in }}$ on each external façade, resulting in a volume flux $Q_{\text {in }}$ through the space.

Previous studies of CV flows in such rectangular rooms [7] showed that the overall flow pattern depends on the dimensionless ratio between the inflow area and the room cross-section, $A^{*}=A_{\text {in }} / A_{\mathrm{RM}}$, where the cross-sectional area is $A_{\mathrm{RM}}=W \cdot H$. For $A^{*}>1 / 2$ the flow is unidirectional and the room volume is predominantly occupied by an expanded jet with characteristic velocity $\approx U_{i n} / A_{\mathrm{RM}}$, while for lower area ratios, the flow exhibits one or more recirculation regions as the air entrained by the jet returns to the inflow region to be re-entrained [8]. The latter case, $A^{*}<1 / 2$, is the challenge in CV modelling and the focus of this paper.

Modern buildings create increased isolation from the outside environment. This trend is also apparent in current CV designs: while traditional natural ventilation systems tended to use large openings (1-4 $\left.\mathrm{m}^{2}\right)$, recent and foreseeable future systems tend to use smaller openings $\left(0.2-1 \mathrm{~m}^{2}\right.$, leading to $\left.A^{*} \ll 0.5\right)$. The contrast is clear: whereas a traditional system using a $1.5 \mathrm{~m}^{2}$ inflow area in a $30 \mathrm{~m}^{2}$ room implies $A^{*}=0.05$, contemporary building $\mathrm{CV}$ systems 

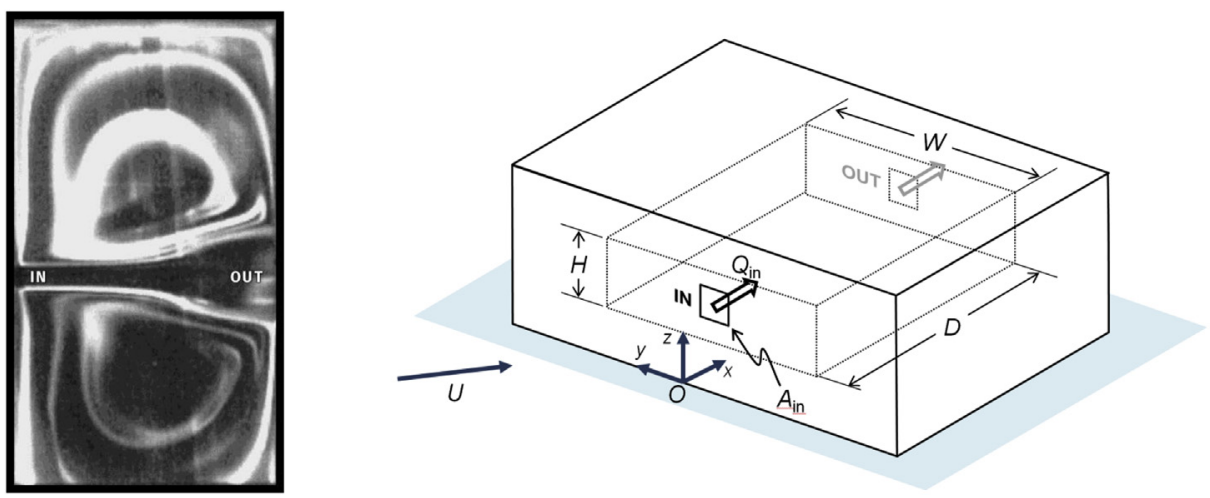

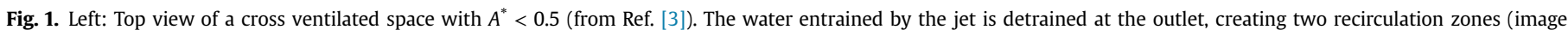
provided by J.E. Wesfreid). Right: Sketch of cross-ventilated rectangular volume.

rely on multiple inflow configurations that allow for efficient heat removal with controlled indoor airflow velocities, leading to a typical $A^{*} \sim 0.01-0.02[9]$.

Although the current state of development of computational fluid dynamics (CFD) simulation tools greatly facilitates engineering design problems there is still a need for simplified models that can provide insight into the mechanisms and geometry features that control CV flows, for example, a set of scaling laws based on the main controlling parameters. The increased insight and computational speed that these models have can facilitate optimization and real time simulation applications. This paper presents a simplified model for CV flow in rectangular volumes with one or more inlet openings facing one or more outlet openings. The model consists of calibrated analytical scaling laws to predict characteristic velocities in the jet and recirculation regions of the flow using as inputs the inflow velocity, and relevant geometry parameters. Although the proposed scaling laws should be applicable to any CV flow it is important to note that the model was developed and tested using a set of CFD simulations that use typical building CV geometries, namely rectangular spaces with $A^{*}<0.05$. Furthermore, in order to model a flow that is in a different flow regime or uses a different fluid, new scaling law constants would need to be obtained.

The next section presents a review of previous research, followed by a set of validated CFD simulations. These are used to determine the multiplying coefficients in the proposed scaling laws for characteristic flow velocities in cross-ventilated spaces. The last part of the paper presents a study of impinging flow angle effects and multiple inflow opening configurations.

\section{Previous research}

In this section we review experimental studies, existing simplified models, and CFD simulations of CV flows with recirculation regions.

\subsection{Experimental studies}

Due to the difficulties in measuring full-scale flows, existing experimental studies of CV flows with recirculations tend to be based on scaled models using air or water as the working fluid. The studies tend to focus on overall flow rate measurement, flow velocities and momentum conservation effects [5,10], providing valuable data that has been extensively used for CFD validation $[11,12]$. Another recent study focused on internal flow in CV [13]. This study used a boundary layer wind tunnel equipped with a motor to rotate a CV building model, simulating the effects of velocity and wind direction fluctuations on the mixing between jet and recirculation regions. This study concluded that most of the pollutant transfer occurs in the shear layers in the edge of the jet, pointing out the short circuit effect that can occur in the core zone of the jet (where fresh air can flow without mixing with recirculation air). Existing studies of full scale CV flows include a detached house [14], and recently, a large residential tower [14]. Both cases provide relevant insights into the mechanisms that control CV flows but still display uncertainties that limit the impact of fullscale studies.

\subsection{Existing simplified models}

Existing experimental correlations for CV flows are based on the principle that average room airflow velocities are proportional to the average airflow velocity at the inflow window. These correlations were developed for particular room geometries and do not consider the effects of room geometry or the existence of jet and recirculation regions in the room [15-17]. A previous model developed by the authors of this paper addressed the need to incorporate room effects and distinguish different flow regions in the room [7]. This model was developed for rooms with a single, large, inflow opening and normal incoming wind. A comparison between the room geometries used to develop and test the previous model [7] and the model proposed in this paper reveals a small overlap in the geometries used:

- Existing model [7]: $2<\mathrm{x}^{*}<18,3.2 \%<\mathrm{A}^{*}<21 \%$

- New model: $12<\mathrm{x}^{*}<36,0.5 \%<\mathrm{A}^{*}<5 \%$

\subsection{CFD simulations of CV flows}

Existing comparisons between experimental CV flows and Reynolds-averaged Navies-Stokes (RANS) CFD simulations provide guidance on the turbulence models that lead to the lowest error in predictions of internal airflow velocities for this type of flow. The first of these studies compared five variants of the $k-\varepsilon$ model for internal natural and mixed convection predictions, including a case with a jet and recirculation, concluding that the standard $k-\varepsilon$ and RNG $k-\varepsilon$ were the better performing models [18]. A recent RANS study on wind-driven CV for an isolated cube [11], based on existing measurements [5], indicated that the SST (shear-stress transport) $k-\omega$ model had a better capability to predict the direction of the inflow jet (due to improved capacity to predict external detached flows). Another recent comparison showed that, for a transitional 
wall jet with a recirculation, the SST $k$ - $\omega$ model gave the best results [19]. An earlier study compared the standard $k-\varepsilon$ and RNG (renormalisation group) $k-\varepsilon$ models for prediction of internal CV flows in a wind tunnel scaled model, concluding that the RNG model is superior to the standard $k-\varepsilon$ model [20]. A CFD validation based on a full-scale isolated single zone $\mathrm{CV}$ building reached a similar conclusion [21]. A recent numerical study focused on the effects of room depth on CV flows, confirming the existing thumb rule of a recommended room depth to ceiling height ratio of less than five $(\mathrm{D} / \mathrm{H}<5)[22]$. Another relevant $\mathrm{CFD}$ based $\mathrm{CV}$ study focused on the impact of roof angle and opening location [23]. Simulations of CV flows with recirculations can also be found in modern design analysis [24].

CFD has also been used to study CV configurations with multiple inflow jets, including a successful validation for simulation of 2D CV flows with merging plane jets (using the standard RNG and Reynolds-stress $k-\varepsilon$ models [25]), and a study of the merging distance for two parallel plane jets (using the standard $k-\varepsilon$ model, with good agreement [26]).

\subsection{Analytical solutions}

Although there is no analytical solution for a complete CV flow, there is relevant previous work that covers the two main flow components. Consider first the jet region. For the simpler case of an unconfined jet there is a solution for the jet velocity profile in the self-similar region that occurs after the initial potential core shear layer development region.

Fig. 2 shows a schematic representation of an axisymmetric jet becoming self-similar approximately six diameters from the outlet. If these solutions are applicable to the confined jets that are found in $\mathrm{CV}$ then the average jet velocity and air entrainment rate can be calculated in a straightforward way. An existing study for medical application used this expression for confined jet flows [4], concluding that free jet self-similar solutions can be applied to the core region of the confined jet, with a small correction factor to increase velocity decay for the cases with larger jet to volume crosssectional area ratios $\left(A^{*}>0.1\right.$, in order to model the increased momentum dissipation at the confining walls). This confined turbulent air jet flow study used an $A^{*}$ range of $0.035-0.25$, providing some overlap to the range relevant to natural CV discussed below.

Simplified modelling of recirculation flow is difficult because it is a secondary flow feature, driven by momentum transfer in the shear layer at the edge of the jet [8]. However, the geometry and behaviour of the flow in these regions resembles a lid-driven cavity

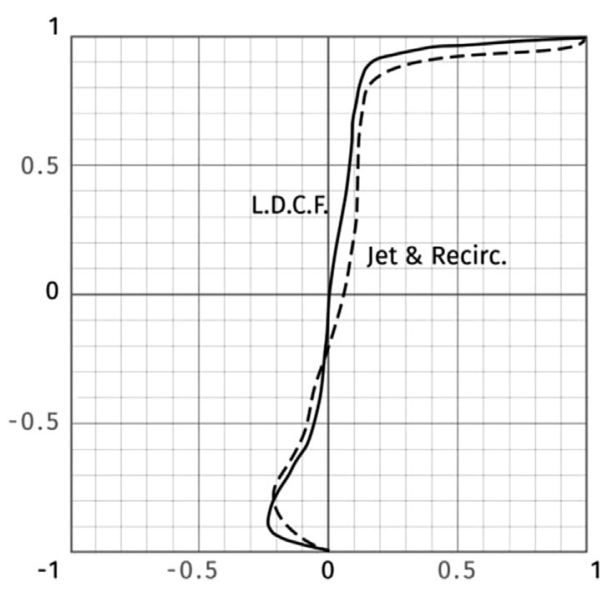

Fig. 3. Comparison between measured velocities in an LDCF [28] and CV flow [19]. Horizontal axis: non-dimensional $x$-velocity. Vertical axis: non-dimensional depth in the cavity (the cavity lid, $\mathrm{y}=1$, cavity floor, $\mathrm{y}=-1$ ).

flow (LDCF), a configuration that has been extensively studied, both numerically and experimentally [27]. An LDCF is the recirculating flow that results from a 'lid' driven across the open face of a cavity at a constant velocity. An existing experimental study used a water model to investigate transitional LDCF flows $(R e=3200)$ concluding that these flows exhibit self-similar velocity profiles [28]. Fig. 3 compares the recirculation region velocity profile from Ref. [17] with experimental results for a 2D CV flow at $R e=2500$ [12], and confirms the similarity between the recirculation flow that results from these two, apparently different, geometries: the average ratio between maximum velocity in $2 \mathrm{D}$ jet and maximum velocity in recirculation is approximately 4.5 in the LDCF and 4.4 in 2D CV flow (Fig. 3).

\section{Modelling approach}

The main hypothesis of the model is the characterization of the $\mathrm{CV}$ flow as a jet driving the recirculation regions as a lid driven cavity flow (Fig. 4). This hypothesis involves two main premises:

- The jet region of the flow can be characterized using an unconfined jet solution.

- The flow in the recirculation regions is similar to an LDCF.

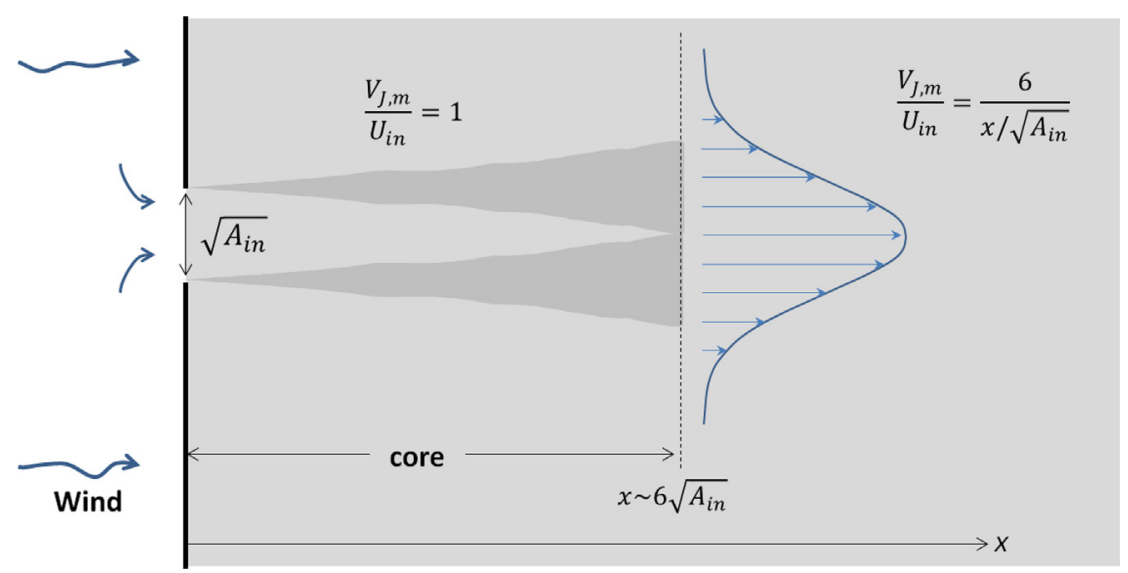

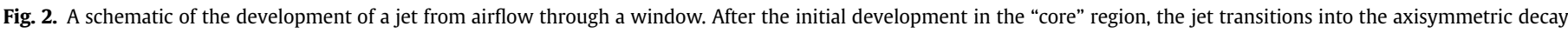
region. 

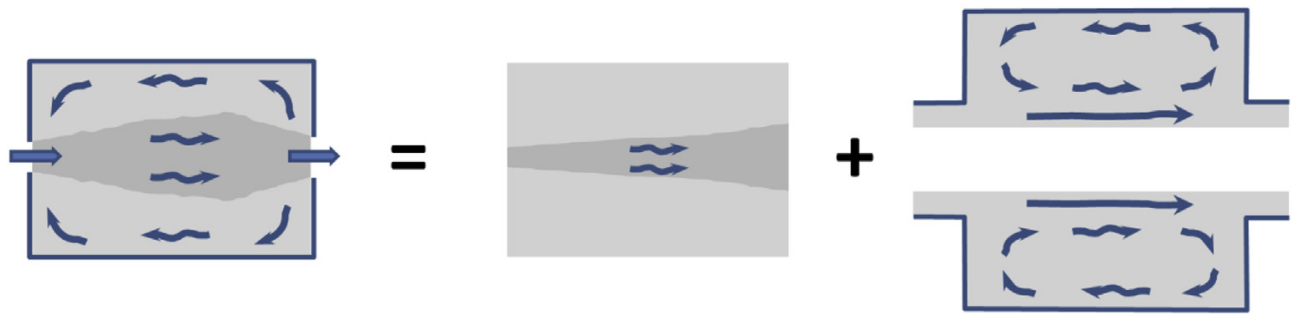

Fig. 4. Top view of a CV flow, approximately composed of a confined jet and two lid-driven cavity flows (one on each side of the jet).

The interrelation between jet and LDCF is apparent in the increased entrainment of the confined jet when compared to a free jet [8]. This increased entrainment as the recirculation flow increases is visible in the time evolution of the jet volume flux after it enters an initially stagnant rectangular volume: Fig. 5 shows the predicted variation of the jet flow rate along the depth of a CV space (results of a transient CFD simulation, using the RNG $k-\varepsilon$ turbulence model). Initially, near the inlet, the recirculation regions that form in the space between the jet and the lateral walls are driven by momentum flow from the confined jet just like the entrainment process that occurs in a free jet. Before the jet leaves the volume it rejects the entrained flow, which is then re-entrained by the jet, progressively building up a recirculation flow rate that exceeds the entrainment rate of a free jet. In the case shown in Fig. 5 the ratio between jet overall flow rate and inflow rate is 6.4 versus 4.3 for the classical non-confined entrainment solution [29], an increase of approximately $50 \%$ due to the cumulative build-up of jet entrainment in the recirculation regions. Clearly the flow in the recirculation regions is under-predicted using unconfined jet entrainment theory; further, as shown in Fig. 3, the recirculation flow is similar to the LDCF profile. The next sections discuss the role in the proposed model of dimensional analysis, flow similarity and experimental results. In the remainder of this paper, we focus on the case of the rectangular enclosed volume, representing a cross-ventilated room, as illustrated in Fig. 1.

\subsection{Dimensional analysis}

Dimensional analysis is a problem simplification approach, widely used in many engineering fields, that consists in identifying the minimum set of non-dimensional variables required to model a given physical system [30]. The most commonly used non dimensional variable is the Reynolds number.

The parameters that we propose to use in the non-dimensional analysis are the depth $D$ (i.e. the distance from the inflow to the outflow vents), the cross-sectional area $A_{\mathrm{RM}}$, and the inflow aperture area $A_{\text {in }}$. With these parameters we compose two nondimensional variables that will be used in the model (previously tested in Ref. [7]):

$$
D^{*}=\frac{D}{\sqrt{A_{i n}}}, A^{*}=\frac{A_{i n}}{A_{R M}}
$$

The length $A_{i n}^{1 / 2}$ is an effective diameter for the inlet, and characterizes the jet geometry. $D^{*}$ is analogous to the normalized coordinate along the jet trajectory, $x^{*}=x / A_{i n}^{1 / 2}$, used in free jet flow characterization (see Section 3.3, below). The simplified nature of the model excludes detailed geometric aspects, such as the shapes of the apertures, their positions in the façade, and alignment between inflow and outflow apertures.

\subsection{Flow similarity}

In the present context, the principle of flow similarity can be stated thus: for a given fluid and volume geometry with a stable flow regime (laminar or turbulent), there is a unique linear relation between inflow velocity and airflow velocity at a given point in the flow, i.e.

$$
V(x, y, z)=U_{\text {in }} \cdot F(x, y, z)
$$

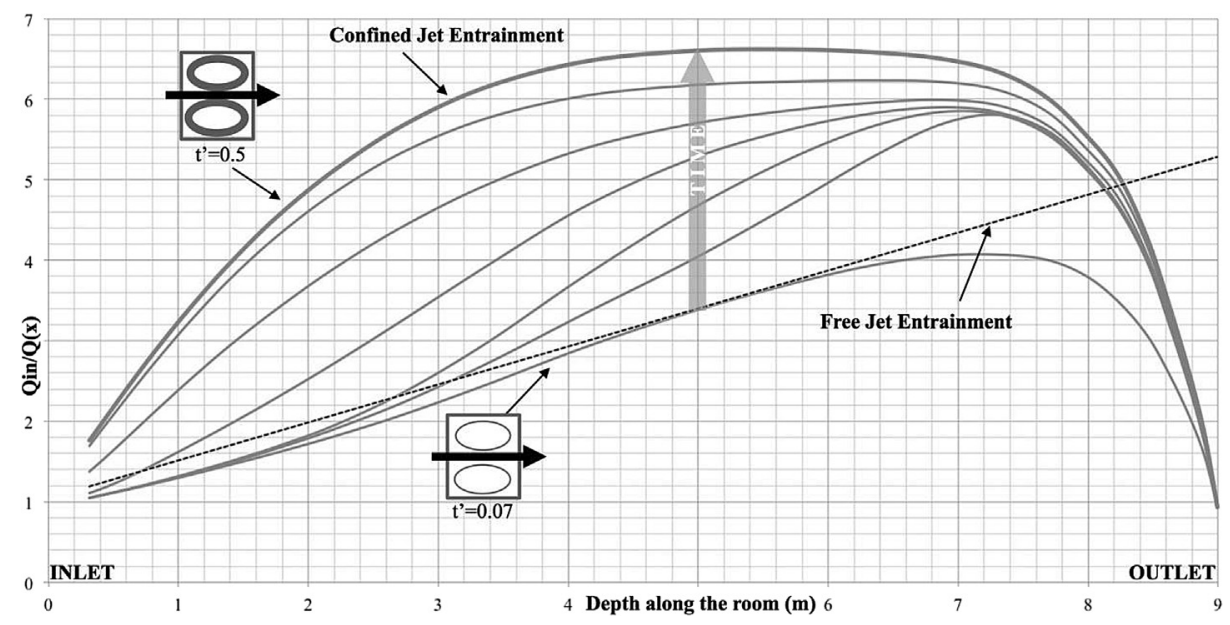

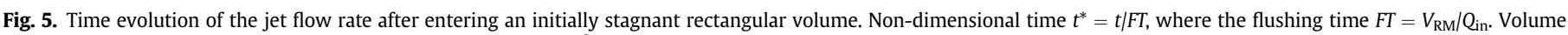

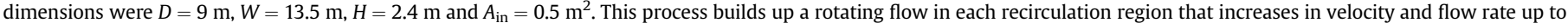

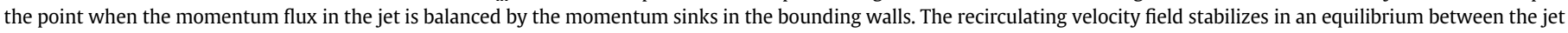
momentum source and the viscous dissipation momentum sinks (in the walls). 
where the non-dimensional function $F$ varies with volume geometry, fluid properties, flow regime and position in the flow [30]. The coordinate system adopted has the $x$-coordinate along the room depth, the $z$-coordinate vertically upwards and the $y$-coordinate across the flow (Fig. 1). For the simplified two-zone model proposed in this study, the function $F$ depends only on the region of the flow - jet or recirculation region - and the two non-dimensional variables $A^{*}$ and $D^{*}$ :

$F(x, y, z)=C_{n} \cdot f\left(A^{*}, D^{*}\right)$

where the constant $C_{\mathrm{n}}$ depends on the region of the flow and, in principle, can be obtained experimentally or from a numerical flow simulation (CFD). From flow similarity one can expect flow velocity in the recirculation region to scale linearly with average jet region velocity. The jet region is defined as the volume bounded at each point $x$ along the room depth by the curve in the $y-z$ plane where the jet velocity drops to $50 \%$ of its maximum centreline value, thereby ensuring that the jet region is a flow volume that is clearly dominated by the jet behaviour. The recirculation regions are defined as all points in the flow where the $x$-velocity $u$ is negative, i.e. its boundary corresponds to $u=0$.

\subsection{Jet and recirculation regions: experimental results (self-similar velocity profiles)}

The characteristic velocity in the jet region is estimated from the free jet centreline velocity $V_{\mathrm{J}, \mathrm{m}}$ averaged along the room depth (Fig. 2), for which analytical expressions are available [31]. The initial portion of free jet flow, the potential core, is characterized by shear layer development along the perimeter of the jet, so that here $V_{\mathrm{J}, \mathrm{m}}=U_{\mathrm{in}}$. After this phase the jet transitions into a self-similar profile whose centreline velocity decays as $1 / x^{*}$. Thus

$V_{j, m} / U_{i n}=\left\{\begin{array}{ccc}1 & x^{*} \leq x_{C}^{*} \\ K / x^{*} & x^{*} \geq x_{C}^{*} \quad(\text { self }- \text { similar profile })\end{array}\right.$

A review of experimental studies of turbulent round jets [32] shows that typical values of $K$ range between five and seven. The core region length $x_{\mathrm{c}}$ extends from the inflow point up to 5-10 inflow diameters. For simplicity, this study adopts an average value of 6 for both $K$ and $x_{c}^{*}$. To estimate the average jet velocity we integrate along the depth of the room, including both the core region and the $1 / x^{*}$ velocity decay region, to derive an average maximum jet velocity, $\overline{V_{j, m}}$ which will be used as the characteristic jet region velocity scale:

$\overline{V_{j . m}}=U_{i n} \cdot \frac{1}{D^{*}}\left\{6+6 \cdot \ln \left(\frac{D^{*}}{6}\right)\right\}$

This expression is valid for rooms whose depth is larger than six jet characteristic diameters, a condition that holds true for all relevant model applications. For shorter rooms we simply have: $\overline{V_{j, m}}=U_{\text {in. }}$.

In many CV applications inflow openings, such as windows and doors, have diverse shapes, ranging from a square opening to a vertical or horizontal slot. Two existing studies analysed the effect of variable orifice shape in three-dimensional free jets (with aspect ratios as large as ten) and proposed a small adjustment in the decay constant $K$ of less than $10 \%[33,34]$. This effect is ignored in the present model.

Analysis of the CFD CV flow simulations that will be presented in the next sections revealed that the room containment effect leads to higher velocities for cases that combine a large inflow opening with a small room cross-sectional area. To account for this flow containment behaviour the model multiplies the average free jet velocity, expression (5), by the non-dimensional scaling parameter $A^{* 1 / 2}$.

\subsection{The combined model}

The model expressions combine the three approaches mentioned above. For conciseness we present the expressions for the challenging cases: $A^{*}<1 / 2$ and $D^{*}>6$. The volume-averaged jet region velocity is predicted using the following expression:

$V_{J}=C_{V, J} \cdot U_{\text {in }} \cdot \frac{\sqrt{A^{*}}}{D^{*}}\left\{6+6 \cdot \ln \left(\frac{D^{*}}{6}\right)\right\}$

The correlation constant $C_{V, J}$ is needed because (5) predicts average maximum centreline velocity whereas $V_{\mathrm{J}}$ refers to a volume-average over the jet region. As discussed, this constant will be obtained from the set of CFD simulations presented below that also tests the validity of the simplified formula proposed. The recirculation region velocity also scales with the driving jet velocity; therefore the model uses a similar expression for this region with a different correlation constant:

$V_{R}=C_{V, R} \cdot U_{\text {in }} \cdot \frac{\sqrt{A^{*}}}{D^{*}}\left\{6+6 \cdot \ln \left(\frac{D^{*}}{6}\right)\right\}$

To predict the maximum recirculation flow rate $Q_{R}$ we multiply the average velocity by the room cross-section area $A_{R M}$ and use a third correlation constant $C_{Q R}$ :

$Q_{R}=C_{Q, R} \cdot U_{i n} \cdot \frac{A_{R M} \sqrt{A^{*}}}{D^{*}}\left\{6+6 \cdot \ln \left(\frac{D^{*}}{6}\right)\right\}$

Because of the self-similar velocity profile in the recirculation, the near-wall velocity (used to predict forced convection) can be estimated by multiplying the characteristic recirculation velocity by two. The correlation expressions obtained apply in the turbulent regime that occurs for the flow velocities found in typical CV flows. The CFD simulations used to obtain the correlation constants $C_{\mathrm{V}, \mathrm{J}}$, $C_{\mathrm{V}, \mathrm{R}}$ and $C_{\mathrm{QR}}$ are also for that regime. For this reason the correlations presented below have the functional form

$V_{n}=a v+b$

where $n$ can be 'J' or ' $\mathrm{R}$ ' (for jet and recirculation regions, respectively), $v$ is a velocity scale, and $a$ and $b$ are constants resulting from a least-squares fit. The model has a lower limit on the value of $v$ : if it is too small the flow is no longer turbulent. This limit implies that the point $v=0$ is never achieved, avoiding the unrealistic prediction of $V_{\mathrm{n}}(0)=b$. Table 1 shows the definition of all variables predicted by the model. Table 2 shows the geometric dimensions of the cases used to test and develop the model.

\section{CFD simulations}

The role of CFD in the model is two-fold: test the validity of the assumptions and obtain the correlation constants that best fit the range of room geometries considered below. This is achieved by running a series of test cases, each with a different room geometry, processing the results to obtain the flow variables defined in Table 1, and then seeking linear relationships between the flow variables and their corresponding scaling expressions (the constants $C_{V J}, C_{V, R}$, and $C_{Q, R}$ in equations (6)-(8)). In the rest of this section, we describe the physical configurations modelled, the setting-up of the CFD model and conclude with a discussion of validation that was carried out. 
Table 1

Definitions of output variables.

\begin{tabular}{|c|c|c|c|}
\hline Output variable & Symbol & Units & Definition \\
\hline Jet velocity & $V_{\mathrm{J}}$ & $\mathrm{m} / \mathrm{s}$ & $\begin{array}{l}\text { Volume-averaged jet region velocity. } \\
\text { The averaging volume is bounded at } \\
\text { each point }(x) \text { along the room depth } \\
\text { by the line in the } y-z \text { plane where the } \\
\text { jet velocity drops below } 50 \% \text { of its } \\
\text { maximum (centreline) value. }\end{array}$ \\
\hline $\begin{array}{l}\text { Recirculation } \\
\text { zone velocity }\end{array}$ & $V_{\mathrm{R}}$ & $\mathrm{m} / \mathrm{s}$ & $\begin{array}{l}\text { Area-averaged velocity in the } y-z \text { plane } \\
\text { with maximum flow. The averaging area } \\
\text { is the recirculation part of the room } \\
\text { cross-section. Typically the plane of } \\
\text { maximum flow occurs at } x \sim 2 D / 3 \\
\text { ( } D / 3 \text { before the outlet). }\end{array}$ \\
\hline $\begin{array}{l}\text { Recirculation } \\
\text { zone flow rate }\end{array}$ & $Q_{R}$ & $\mathrm{~m}^{3} / \mathrm{s}$ & $\begin{array}{l}\text { Total flow rate for the recirculation } \\
\text { regions in the plane of maximum flow } \\
\text { (see above). }\end{array}$ \\
\hline
\end{tabular}

\subsection{Configurations modelled}

As discussed above the model correlation constants were obtained for airflow in naturally cross-ventilated buildings. Therefore the physical set-up simulated in each case consisted of an isolated building in which a single rectangular room was cross-ventilated by a steady mean wind that is perpendicular to the inflow window. Contemporary building CV systems have $A^{*}$ in the range: $0.01-0.02$ [9]. Further, for the typical airflow velocities and aperture dimensions used in building ventilation, the CV flow is invariably turbulent $\left(v \approx 0.5 \mathrm{~m} / \mathrm{s}, A_{\text {in }} \approx 0.5 \mathrm{~m}^{2} \Rightarrow \operatorname{Re}>10^{5}\right)$. The details of each aspect are described below.

\section{a) Building}

The building was cuboidal in shape with width $24 \mathrm{~m}$, height $9 \mathrm{~m}$ and depth $0.2 \mathrm{~m}$ greater than the room depth (corresponding to a $0.1 \mathrm{~m}$ thickness to the external walls and window openings). It is representative of a small 3-story office building at full-scale. While the room geometry was varied, the building geometry and the incoming wind (normal to the openings) were fixed.

\section{b) Room}

The building contains a single room open to the external environment, with one opening in each of the two principal façades. In the default configuration the two openings are of equal size and opposite one another in the centre of each wall and positioned midway between floor and ceiling. The room itself is positioned centrally both horizontally and vertically with respect to the building façade, and is therefore representative of a second-floor
Table 3

Percentage error in $x$-velocity profile using different flow metrics.

\begin{tabular}{llll}
\hline & RNG $k-\varepsilon(\%)$ & SST $k-\omega(\%)$ & Average $(\%)$ \\
\hline Mean jet velocity $\left(V_{\mathrm{J}}\right)$ & 1 & 12 & 5 \\
Mean return velocity $\left(V_{\mathrm{R}}\right)$ & 6 & 1 & 3 \\
Mean return flow $\left(Q_{\mathrm{R}}\right)$ & 7 & 5 & 7 \\
\hline
\end{tabular}

office. Rooms with $H=2.3 \mathrm{~m}$ were positioned midway between the ground and the building roof, while the taller rooms with $H=3.4 \mathrm{~m}$ were realized by keeping the floor level fixed and moving the ceiling up.

Table 3 lists the room geometries used to develop the model. The database contains the typical room sizes for which single opening CV systems may be used, ranging from a small office $(4.5 \mathrm{~m} \times 4.5 \mathrm{~m} \times 2.3 \mathrm{~m})$ up to a large space $(13.5 \mathrm{~m} \times 18 \mathrm{~m} \times 2.3 \mathrm{~m})$. Room height $H$ varied between $2.3 \mathrm{~m}$ and $3.4 \mathrm{~m}$ and the inflow aperture area $A_{\text {in }}$ varied between 0.25 and $1 \mathrm{~m}^{2}$.

\section{c) Wind and environment}

The wind speed was $10 \mathrm{~m} / \mathrm{s}$ at $10 \mathrm{~m}$ reference height, and taken to be appropriate to an urban boundary layer (see also the discussion of velocity inlet boundary conditions below).

\subsection{CFD set-up}

All CFD simulations were performed with the code ANSYS ${ }^{\circledR}$ FLUENT, Release 14.0 and 14.5, using the steady pressure-based solver. Under the categories below we describe how the physical configurations defined above were translated into CFD input, how convergence was monitored and how results for use in developing the correlations were obtained.

\section{a) Computational domain and grid}

In order to model the flow inside the room in a more realistic way, both this flow and the external flow around the building were modelled together (rather than, say, using a separate stage to generate the conditions at the inlet aperture). The disadvantage is that the computational domain must be large enough to avoid undue influence of the boundaries of the domain on the building flow, but at the same time able to resolve the flow across the apertures and within the room adequately. A structured grid was used whose overall dimensions were based on standard recommendations [35] that use the building height as the appropriate scale: thus the limits in each coordinate direction were $-5 H \leq x \leq 15 H,-W / 2-5 H \leq y \leq W / 2+5 H, 0 \leq z \leq 6 H$. This was

Table 2

Test cases used to develop correlations.

\begin{tabular}{|c|c|c|c|c|c|c|c|c|c|}
\hline Case & $\begin{array}{l}\text { Opening area } \\
A_{\text {in }}\left(\mathrm{m}^{2}\right)\end{array}$ & $\begin{array}{l}\text { Room width } \\
W(\mathrm{~m})\end{array}$ & $\begin{array}{l}\text { Room depth } \\
D(\mathrm{~m})\end{array}$ & $\begin{array}{l}\text { Room height } \\
H(\mathrm{~m})\end{array}$ & Case & $\begin{array}{l}\text { Opening area } \\
A_{\text {in }}\left(\mathrm{m}^{2}\right)\end{array}$ & $\begin{array}{l}\text { Room width } \\
W(\mathrm{~m})\end{array}$ & $\begin{array}{l}\text { Room depth } \\
D(\mathrm{~m})\end{array}$ & $\begin{array}{l}\text { Room height } \\
H(\mathrm{~m})\end{array}$ \\
\hline 1 & 0.25 & 4.5 & 4.5 & 2.3 & 11 & 0.5 & 13.5 & 9.0 & 3.4 \\
\hline 2 & 0.25 & 6.0 & 9.0 & 2.3 & 12 & 0.5 & 13.5 & 18.0 & 2.3 \\
\hline 3 & 0.25 & 11.0 & 9.0 & 2.3 & 13 & 0.75 & 6.0 & 9.0 & 2.3 \\
\hline 4 & 0.5 & 6.0 & 9.0 & 2.3 & 14 & 0.75 & 11.0 & 9.0 & 2.3 \\
\hline 5 & 0.5 & 9.0 & 6.0 & 2.3 & 15 & 0.75 & 13.5 & 18.0 & 2.3 \\
\hline 6 & 0.5 & 9.0 & 9.0 & 2.3 & 16 & 1.0 & 9.0 & 9.0 & 2.3 \\
\hline 7 & 0.5 & 9.0 & 13.5 & 2.3 & 17 & 1.0 & 9.0 & 9.0 & 3.4 \\
\hline 8 & 0.5 & 9.0 & 18.0 & 2.3 & 18 & 1.0 & 9.0 & 13.5 & 2.3 \\
\hline 9 & 0.5 & 11.0 & 9.0 & 2.3 & 19 & 1.0 & 9.0 & 13.5 & 3.4 \\
\hline 10 & 0.5 & 13.5 & 9.0 & 2.3 & 20 & 1.0 & 9.0 & 18.0 & 2.3 \\
\hline \multicolumn{6}{|c|}{ Ranges (max:min ratio) } & 4.0 & 3.0 & 2.0 & 1.5 \\
\hline
\end{tabular}


adjusted in cases where the wind was not aligned with the x-direction so that the boundaries parallel and perpendicular to the wind were sufficiently far away.

The grid resolution was chosen to give precedence to regions of high variation - adjacent to solid walls, and in the shear layers developing downstream of the apertures inside the room - using inflation factors of between 1.1 and 1.2 to expand the cell size away from these areas. The net result was a grid of approximately $1.0-1.5 \times 10^{6}$ cells in total, with $1.2-1.5 \times 10^{5}$ cells within the room.

\section{b) Models}

Two different turbulence models were used in all the simulations, namely the SST $k-\omega$ and RNG $k-\varepsilon$ models, since these had been shown to perform best among the RANS turbulence models in a number of investigations (see Section 2.1). In both cases, the ANSYS ${ }^{\circledR}$ FLUENT “advanced wall treatment" was selected, which assesses the grid resolution and uses wall functions if the grid spacing is sufficiently large.

\section{c) Boundary conditions}

Standard choices for boundary conditions in this type of problem were used in the simulations. At the upstream (inlet) boundary of the computational domain, vertical profiles for the velocity variables were specified: a logarithmic mean velocity profile, specified using the reference velocity and height (Section 4.1(d)) and a roughness height $z_{0}=0.3 \mathrm{~m}$ appropriate to an urban boundary layer profile; and turbulence variables $(k, \varepsilon, \omega)$ as given by Ref. [11]. The downstream face was treated as a constant (zero) pressure boundary; while the top and side boundaries were assigned symmetry conditions (zero gradient). Solid surfaces were specified as no-slip boundaries.

\section{d) Numerical scheme}

Second-order accurate schemes were selected for all the equations.

\section{e) Convergence monitoring}

The standard practice in monitoring convergence is to track both the residuals for each equation and some pointwise or integral properties of the solution as the simulation progresses, and to consider the solution converged when the residuals are all less than some small threshold, such as $10^{-4}$ and the variation in the flow properties is likewise less than a specified tolerance. In most cases here the residuals were unsuitable monitors since they levelled off at least an order of magnitude above this threshold, so the primary convergence monitors used were instead the correlation parameters themselves, i.e. $V_{\mathrm{J}}, V_{\mathrm{R}}$, etc. These parameters showed a variety of behaviour, ranging from convergence to constant values in some cases, to oscillations of varying amplitude in others. Each simulation was therefore run until one or other of these behaviours was observed - continuing the simulation for additional numbers of iterations - and then averaging the results over a sufficient number of iterations, typically 1000 , to at least two oscillation periods and smooth out the variations. The quasi-steady nature of the CFD solution was also observed by Ref. [11] in simulations of similar geometries. It is probably due to conflict between the attempt to find a steady solution to the problem and the intrinsically unsteady nature of the combined exterior/interior flow. This effect was dependent on the choice of turbulence model: the two main models used in these simulations (SST $k-\omega$ and RNG $k-\varepsilon$ ) both exhibited this behaviour, while the standard $k-\varepsilon$ model did not, which is likely to reflect the ability of a given model to capture features leading to unsteadiness.

\section{f) Post-processing}

The flow variables defined in Table 1 are averages over volumes or areas whose boundaries depend on the flow, e.g. the surface of $50 \%$ maximum centreline $x$-velocity used in the definition of $V_{\mathrm{J}}$. The standard post-processing capabilities of ANSYS $^{\circledR}$ FLUENT are insufficient to calculate these parameters, and so the UDF (userdefined function) facility was used. UDF's are routines written in C that can be called during a simulation; in this case, the UDF was called at the end of each iteration to calculate the flow parameters and write their values to a file, which can be examined either during a run or at the end of a batch of iterations.

\subsection{Validation}

There are no published experimental studies of detailed flow fields inside a cross-ventilated space for the geometries considered here. An existing study [11] investigated the simulation of the experimental results of [5] using ANSYS ${ }^{\mathbb{B}}$ FLUENT and found that velocity profiles deduced from PIV measurements across the small model-scale test room $(0.1 \mathrm{~m} \times 0.1 \mathrm{~m} \times 0.08 \mathrm{~m})$ could be
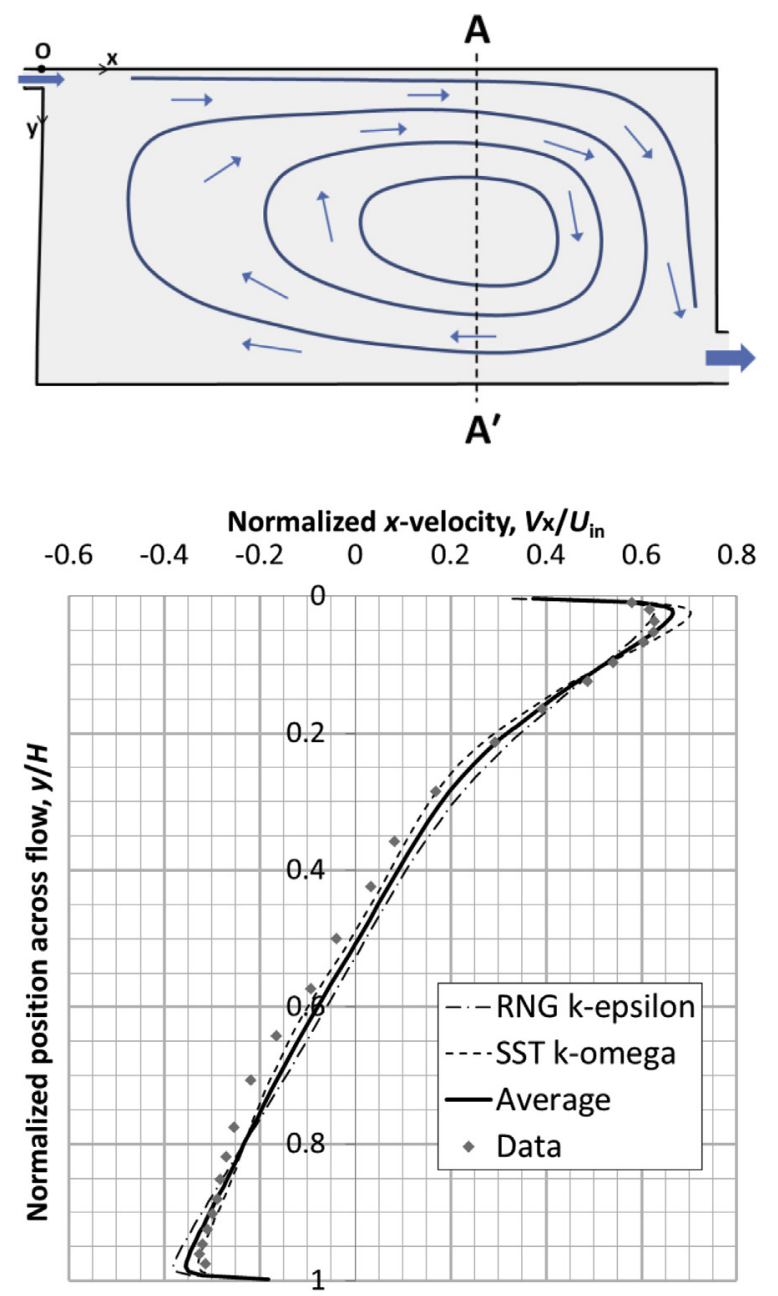

Fig. 6. Comparison of CFD simulation of diffuser flow with experimental data using two different turbulence models. The graph plots the profile of $x$-velocity (normalized with the inflow velocity) along the cross-section AA'. 
adequately reproduced. This result was exploited by basing the computational set-up here on the successful set-up in Ref. [11] and therefore by-passing the need for extensive validation runs.

Validation of the flow rate for a room/building geometry essentially identical to that used in the test runs was carried out using recent data from wind tunnel studies [36]. In these tests the $\mathrm{CV}$ flow rate was inferred from concentration decay rates of a passive tracer initially filling the model room. ANSYS ${ }^{\circledR}$ FLUENT was first run to generate the steady flow field; this was then used to drive the time-evolution of the concentration field in a transient simulation, starting from a volume uniformly seeded with tracer gas. The computed decay rates agreed very well with the observations for a number of different aperture arrangements.

A further validation exercise was carried out to confirm the suitability of CFD modelling to the CV flows of interest. For this purpose a previously studied test case $[10,37]$ was simulated in a steady 3-D run of ANSYS ${ }^{\circledR}$ FLUENT, consisting of a rectangular volume with a single two-dimensional inlet and outlet (Fig. 6). The computational grid comprised $4 \times 10^{5}$ cells, with 10 cells across the inlet and 20 across the outlet. The simulation was carried out at a scale appropriate to a CV room, with cross-sectional dimensions $9 \mathrm{~m} \times 3 \mathrm{~m}$ and length $3 \mathrm{~m}$ in the normal direction, and compared with experimental data at model scale $(1: 33.6)$ but the same inlet Reynolds number $(R e=5000)$.

The graph in Fig. 6 compares the velocity profile in a plane twothirds of the way along the flow, showing good agreement with the experimental results. Note that this is the same location relative to the inlet at which the maximum flow rate typically occurs in CV flows. Besides the pointwise comparison, the CV correlation parameters, $V_{\mathrm{J}}, V_{\mathrm{R}}$ and $Q_{\mathrm{R}}$, were also computed using suitable definitions for this set-up: for example, the mean jet velocity, $V_{\mathrm{J}}$, is the average over the part of AA' for which the flow is positive and exceeds $50 \%$ of the maximum value. Comparisons with the experimental values are given in Table 3, which shows that the CFD simulation predicts the experimental values in general to within $10 \%$.

\section{Results}

Fig. 7 shows a plan view of the CFD solution field for two cases in the database, case $\# 19\left(W=9 \mathrm{~m}, D=13.5 \mathrm{~m}, H=3.4 \mathrm{~m}, A_{\text {in }}=1 \mathrm{~m}^{2}\right)$ and case \#4 $\left(W=6 \mathrm{~m}, D=9 \mathrm{~m}, H=2.3 \mathrm{~m}, A_{\text {in }}=0.5 \mathrm{~m}^{2}\right)$. As expected, both cases clearly display the distinct character of the two flow regions.

Fig. 8 shows plots of the data derived from the CFD simulations of all 20 test cases, including the lines giving the best fit to the data. Each point is obtained by computing for a given case the scaling parameter based on the room parameters ( $x$-axis) and the relevant averaged parameter from the CFD solution ( $y$-axis). The plots test the proposed scalings given in Equations (6)-(8) for $V_{\mathrm{J}}, V_{\mathrm{R}}$ and $Q_{\mathrm{R}}$ : the better scalings are indicated by the smaller scatter of the points around a straight line. As expected, the model error for prediction of jet average velocity, a primary flow feature, is lower than the error for recirculation velocity and flow rate (secondary flow features).

Table 4 gives the quantitative details of these plots, in the form of the best-fit linear correlations for each variable and turbulence model. The minimum quadratic difference correlations are evaluated using the Pearson product-moment correlation coefficient, $r$. Overall the results confirm the modelling assumptions. The precision level of the correlations is variable, with the highest correlation occurring for the jet velocity and the lowest for the recirculation velocity, all are with an average error below $20 \%$. In comparison with the SST $k-\omega$, the RNG $k-\varepsilon$ model gives higher correlation: the average error for the three correlated parameters is $14 \%$ ( $17 \%$ for the RNG $k-\varepsilon$ model).
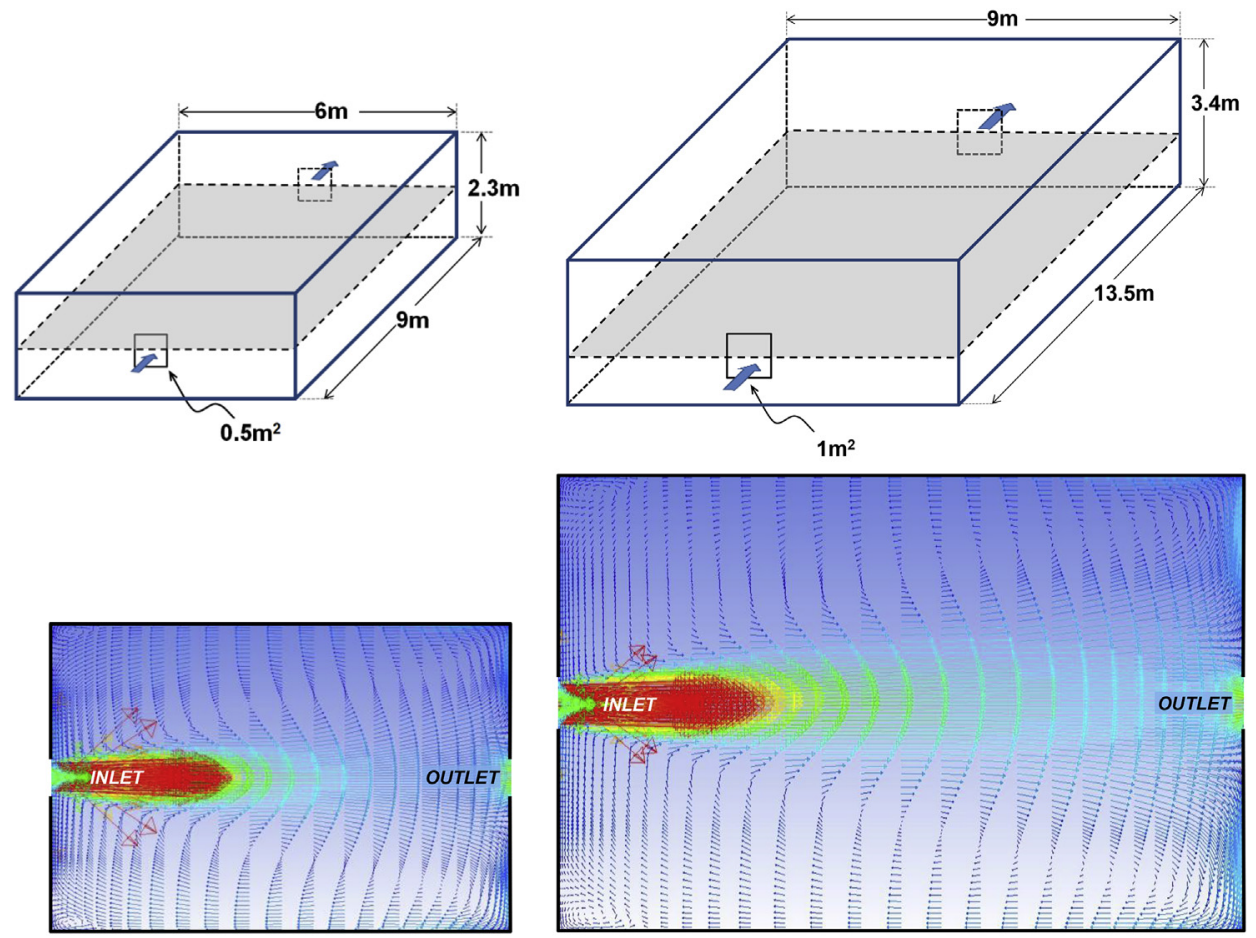

$U(\mathrm{~m} / \mathrm{s})$

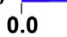

$$
1.0
$$

Fig. 7. Velocity at mid-opening height for Case 4 (left) and Case 19 (right). 

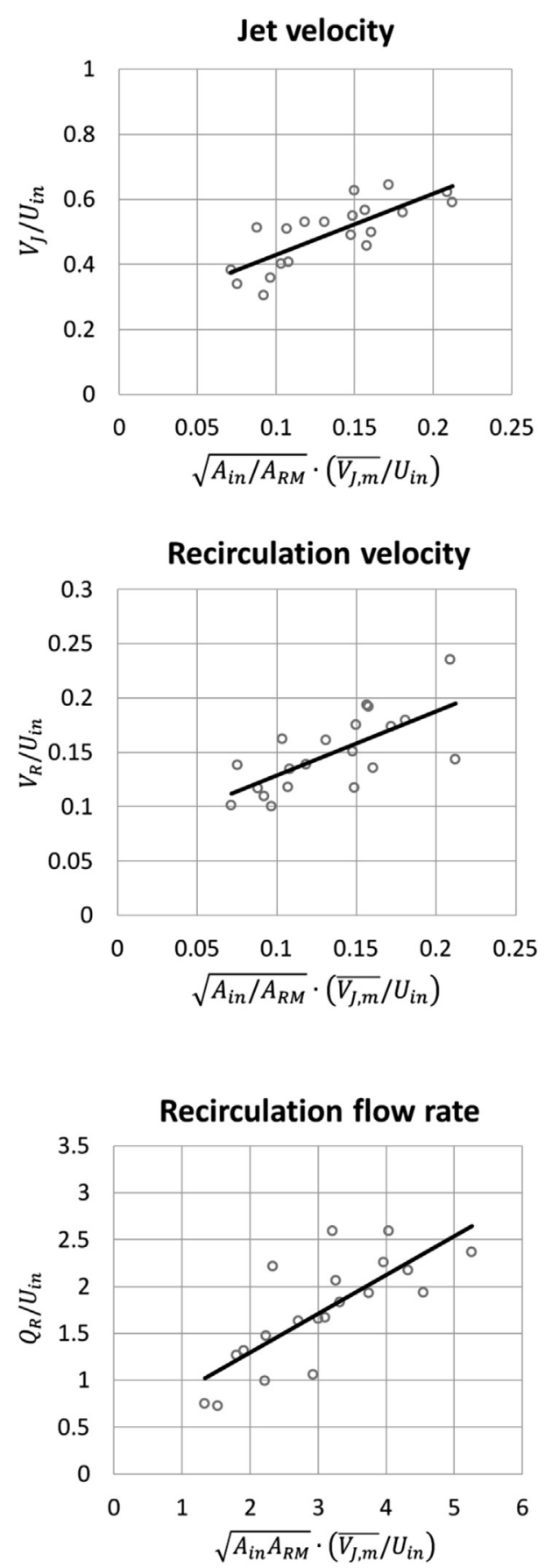

Fig. 8. Correlation results for jet velocity, recirculation velocity and recirculation flow rate using two different turbulence models: RNG $k-\varepsilon$ (left-hand column) and SST $k-\omega$ (right-hand column).

\subsection{Modelling assumptions: sensitivity analysis}

The proposed model neglects the effects of outflow aperture position and buoyancy. In this section, the validity of these simplifying assumptions is analysed using a limited set of CFD simulations with the aim of comparing a base case (Table 3, Case 4, a $6 \mathrm{~m} \times 9 \mathrm{~m} \times 2.3 \mathrm{~m}$ room with $A_{\text {in }}=A_{\text {out }}=0.5 \mathrm{~m}^{2}$ and flow field shown in Fig. 7) with alternate cases where the neglected feature is included in the simulation.

\subsubsection{Outflow aperture position and number}

In order to test the influence of outlet aperture area and position, the following seven variations of the base case were simulated:

(a) Base case with a large outlet, aligned with the inlet, and $A_{\text {out }} /$ $A_{\text {in }}=1.5,2.0,2.5$ and 3.0

(b) Base case with single outlet, offset from the inlet, and $A_{\text {out }} /$ $A_{\text {in }}=1.0,2.0$

(c) Base case with two outlets, offset from the inlet, and $A_{\text {out }, 1}=A_{\text {out }, 2}=0.71 \mathrm{~m}^{2}$ (so that the effective combined area of the two outlets, $A_{\text {out }, 1} \cdot A_{\text {out }, 2} / \sqrt{\left(A_{\text {out }, 1}^{2}+A_{\text {out }, 2}^{2}\right)}$, equals $\left.A_{\text {in }}\right)$.

In the case of (b) and (c), the outlets were offset so that in each case they were midway between the base case outlet position and a side wall.

Table 5 presents a comparison between the base case and the above variations, giving the percentage relative difference for each of the three velocity-related correlation parameters. The table indicates that outlet position and number do not significantly influence internal velocities. The cases for which the outlet was larger than the inlet showed a significant deviation in the recirculation velocities compared with the base case when the outlet was more than twice the inlet area. In these circumstances there would be a large model error, and it is therefore recommended that use of the model should be restricted to cases where $A_{\text {out }} / A_{\text {in }}<2$.

\subsubsection{Effects of buoyancy}

The model does not consider the effect of buoyancy forces on the indoor velocities. These forces are approximately perpendicular to the CV flow inertial forces. The relative importance of buoyancy and momentum fluxes can be assessed by means of the Richardson number $R i=Q B^{1 / 2} / M^{5 / 4}$, where $Q$ is the volume flux, $B$ the buoyancy flux and $M$ the momentum flux. For the cases listed in Table 3, the maximum value of $R i$ was found to be 0.084 , indicating buoyancy effects were unlikely to be important. In order to check this assertion in more detail, the base case was simulated with internal heat gains and buoyancy effects turned on, and with both $100 \%$ and $50 \%$ wind speed. The internal heat gains were distributed uniformly over two cuboidal volumes running parallel to the room depth between the apertures and the side walls (i.e. concentrated in the recirculation regions), and gave $55 \mathrm{~W} / \mathrm{m}^{2}$ averaged over the whole room. For the case with $50 \%$ wind velocity the average inflow velocity was $2 \mathrm{~m} / \mathrm{s}$, equivalent to a $27.5 \mathrm{~W} / \mathrm{m}^{2}$ gain and a $1 \mathrm{~m} / \mathrm{s}$ inflow velocity, conditions that are likely to occur in passive CV buildings. Table 5 shows that the difference in the average jet and recirculation velocities was $11 \%$ or less, confirming the possibility of neglecting buoyancy without compromising modelling precision.

\section{Model extension}

Engineering design cases where the model is expected to be applied are likely to include rooms with multiple inflow apertures and variable impinging flow direction (in the case tested ascribed to the incoming wind). This section presents the extension of the model to handle these two cases.

\subsection{Extension to multiple inflow apertures}

Many CV building designs use multiple inflow openings [9,38]. In these geometries the difference in wind-generated pressure from one side of the building to the other, $\Delta p$, is large compared with the difference in pressure across the inlet façade, so that each window experiences approximately the same pressure. In this case, 
Table 4

Correlation formulae in the form $\mathrm{Y}=\mathrm{aX}+\mathrm{b}$.

\begin{tabular}{|c|c|c|c|c|c|c|c|}
\hline Physical quantity & $\mathrm{Y}$ & $\mathrm{X}$ & Turbulence model & $\mathrm{a}$ & b & $r$ & Average \% error \\
\hline \multirow[t]{3}{*}{ Jet velocity } & $V_{J}$ & & RNG $k-\varepsilon$ & 1.711 & 0.240 & 0.783 & 10 \\
\hline & & & SST $k-\omega$ & 2.035 & 0.245 & 0.740 & 14 \\
\hline & & & Average & 1.873 & 0.243 & 0.781 & 11 \\
\hline \multirow[t]{3}{*}{ Recirculation zone velocity } & $\frac{V_{R}}{U_{i n}}$ & & RNG $k-\varepsilon$ & 0.685 & 0.070 & 0.729 & 14 \\
\hline & & & SST $k-\omega$ & 0.496 & 0.070 & 0.565 & 17 \\
\hline & & & Average & 0.591 & 0.070 & 0.698 & 13 \\
\hline \multirow[t]{3}{*}{ Recirculation zone flow rate } & $\frac{Q_{R}}{U_{i n}}$ & $\sqrt{A_{i n} A_{R M}} \cdot\left(\frac{\overline{V_{j, m}}}{U_{i n}}\right)$ & RNG $k-\varepsilon$ & 0.453 & 0.481 & 0.773 & 17 \\
\hline & & & SST $k-\omega$ & 0.376 & 0.451 & 0.726 & 19 \\
\hline & & & Average & 0.415 & 0.466 & 0.767 & 18 \\
\hline
\end{tabular}

Table 5

Sensitivity test results, showing percentage relative difference in correlation parameters compared with the base case.

\begin{tabular}{lccc}
\hline & \multicolumn{3}{c}{ Difference from base case (\%) } \\
\cline { 2 - 4 } & $V_{\mathrm{J}}$ & $V_{\mathrm{R}}$ & $Q_{\mathrm{R}}$ \\
\hline$A_{\text {out }}=1.5 A_{\text {in }}$ & 2 & 3 & 3 \\
$A_{\text {out }}=2.0 A_{\text {in }}$ & 1 & 4 & 4 \\
$A_{\text {out }}=2.5 A_{\text {in }}$ & 6 & 43 & 41 \\
$A_{\text {out }}=3.0 A_{\text {in }}$ & 6 & 42 & 40 \\
$A_{\text {out }}=A_{\text {in }}$, outlet offset & 10 & 10 & 8 \\
$A_{\text {out }}=2.0 A_{\text {in }}$, outlet offset & 13 & 7 & 8 \\
2 outlets, same total area $A_{\text {out }}=A_{\text {in }}$ & 5 & 4 & 2 \\
Buoyancy and heat included & 0 & 4 & 3 \\
Buoyancy and heat, half wind speed & 2 & 11 & 10 \\
\hline
\end{tabular}

Table 6

Cases and results for the side-by-side configuration.

\begin{tabular}{|c|c|c|c|c|c|}
\hline & Aperture & & Case A & Case B & Case $\mathrm{C}$ \\
\hline \multirow[t]{2}{*}{$A_{\text {in }}\left(\mathrm{m}^{2}\right)$} & 1 & & 0.5 & 1.0 & 0.5 \\
\hline & 2 & & 0.5 & 1.0 & 1.0 \\
\hline \multirow{4}{*}{$\frac{V_{J}}{U_{i n}}(-)$} & 1 & Side-by-side & 0.428 & 0.542 & 0.427 \\
\hline & & Single & 0.462 & 0.543 & 0.462 \\
\hline & 2 & Side-by-side & 0.421 & 0.545 & 0.561 \\
\hline & & Single & 0.462 & 0.543 & 0.543 \\
\hline \multirow{4}{*}{$\frac{V_{R}}{U_{i n}}(-)$} & 1 & Side-by-side & 0.133 & 0.229 & 0.134 \\
\hline & & Single & 0.124 & 0.209 & 0.124 \\
\hline & 2 & Side-by-side & 0.127 & 0.198 & 0.208 \\
\hline & & Single & 0.124 & 0.209 & 0.209 \\
\hline \multirow{4}{*}{$\frac{Q_{R}}{U_{i n}}\left(\mathrm{~m}^{2}\right)$} & 1 & Side-by-side & 1.306 & 1.880 & 1.312 \\
\hline & & Single & 1.306 & 1.906 & 1.306 \\
\hline & 2 & Side-by-side & 1.340 & 1.814 & 1.904 \\
\hline & & Single & 1.306 & 1.906 & 1.906 \\
\hline
\end{tabular}

if the discharge coefficient, $C_{\mathrm{d}}$, is similar for all apertures, the inflow velocity is also approximately constant for the different openings:

$Q_{i n}^{(i)}=C_{d} A_{i n}^{(i)} \sqrt{\frac{2 \Delta p}{\rho}} \Rightarrow U_{i n}^{(i)}=\frac{Q_{i n}^{(i)}}{A_{i n}^{(i)}}=C_{d} \sqrt{\frac{2 \Delta p}{\rho}}$

However, a constant inflow velocity does not imply a constant jet and recirculation velocity since $A_{\text {in }}$ may vary between openings. For example, a room with two equally spaced inflow openings of area 0.5 and $1.0 \mathrm{~m}^{2}$ will have internal velocities in the jet regions that differ by more than $30 \%$ (the larger opening generating higher velocities as the jet does not decay as much inside the room, see the "Case C" column, in Table 6).

In order to extend the model in the simplest way, we investigated the possibility of approximating the flow through a space with multiple inflow apertures as an equivalent set of independent single-aperture flows arranged side-by-side. Fig. 9 illustrates this concept schematically when there are two inflow apertures; if applied to the flow field illustrated in Fig. 10, it would mean that this $18 \mathrm{~m}$-wide space could be modelled as two $9 \mathrm{~m}$-wide spaces with corresponding inlet areas.

This hypothesis was tested by modelling this space with three different aperture arrangements, Cases A, B and C, as defined in Table 6: for example, Case $A$ has two equal inflow apertures with $A_{i n}^{(1)}=A_{i n}^{2}=0.5 \mathrm{~m}^{2}$. In each case the flow through the space was first modelled as a single room with two inlet apertures, and the jet velocity, etc. computed for each half of the room. These values were then compared with the results of modelling two separate oneinlet spaces. The numerical results are given in Table 6: the
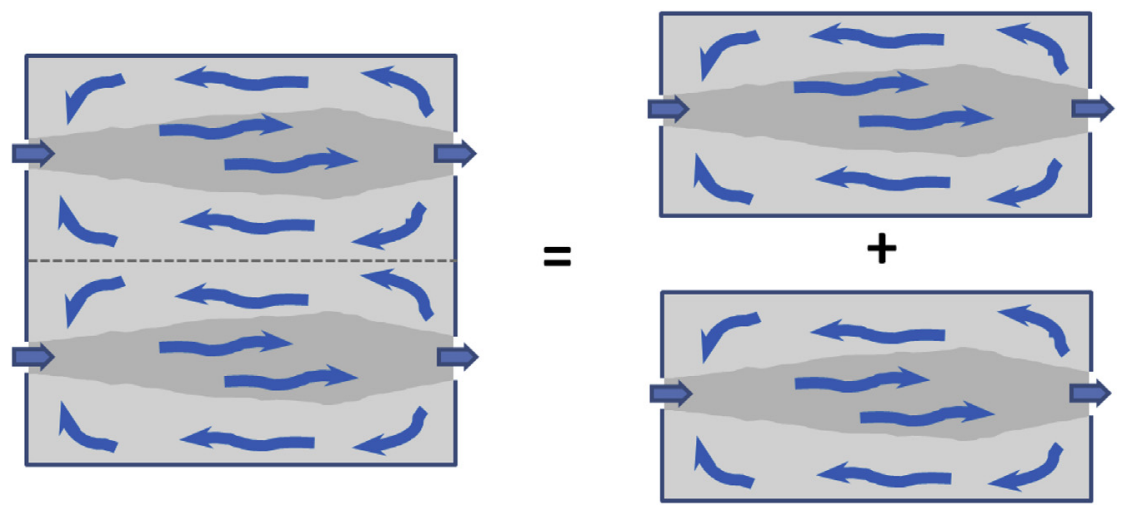

Fig. 9. Schematic illustration of procedure to model a 2-aperture room as a combination of 1-aperture rooms. 


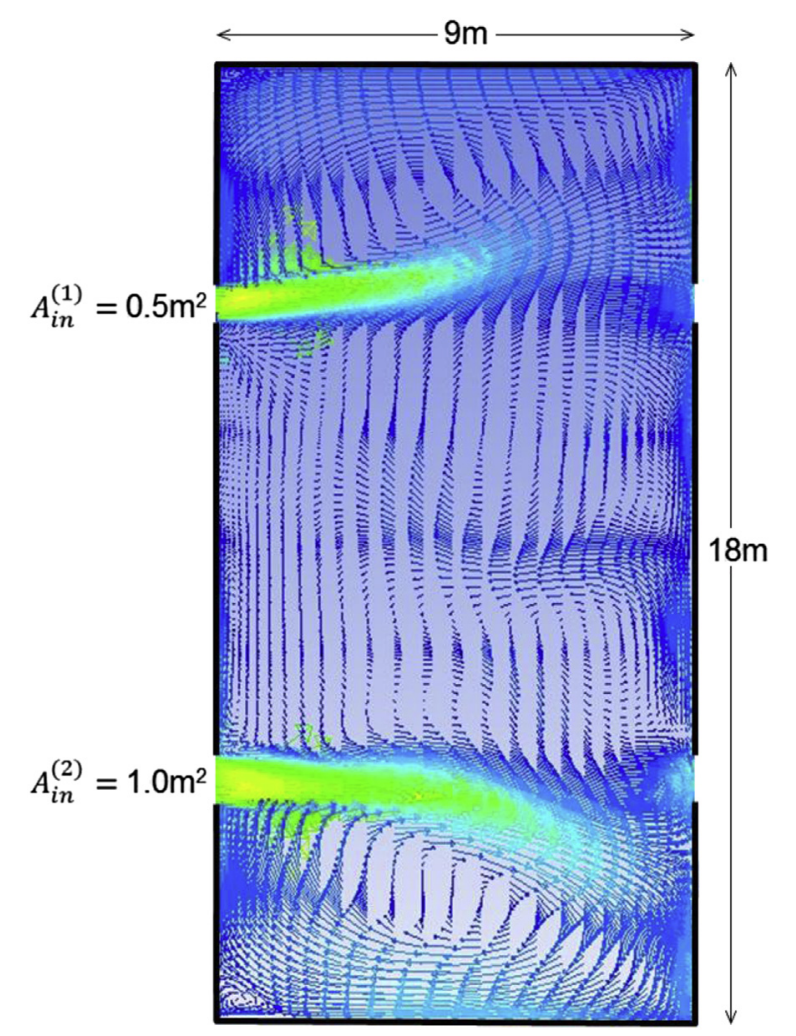

Fig. 10. Top view of velocity field at mid-aperture height for room with $W=18 \mathrm{~m}$, $D=9 \mathrm{~m}, H=2.3 \mathrm{~m}$ and two apertures of $0.5 \mathrm{~m}^{2}$ and $1 \mathrm{~m}^{2}$, corresponding to Case $C$ in Table 6.

accuracy of the approximation is measured by the similarity of each "Side-by-side" value to its corresponding "Single" value.

Detailed analysis of the flow results for the cases shown in Table 6 reveals that the airflow velocities of the 2 -inlet room and the corresponding 1-inlet rooms differ on average by less than $5 \%$ (Fig. 11). These results confirm the possibility of applying the model to multiple inflow openings as a linear addition of adjacent single opening rooms. Further, the quantitative comparisons above suggest that the differences between the 2-inlet CV flow and its 1-inlet "components", visible in the deviation of the jets towards the outlet end of the room in Fig. 10 compared with the flow in Fig. 7, are not significant as far as the (averaged) correlation parameters are concerned. The results presented in this section were obtained for a case with two inflow apertures. Exploratory tests for cases with three and four apertures indicate that the results presented remain valid. Further work would be necessary to quantify the effects of non-aligned apertures and unequal numbers of inlet and outlet apertures.

\subsection{Extension to variable impinging flow direction}

In any real wind-driven CV building, variations in the wind direction are continuously changing the volumetric flow rate and direction of the inflow jets, thereby increasing mixing in the space by exposing the recirculation regions to direct jet flow [13]. For a given room, wind-driven flow rate is a function of the total static pressure difference, whereas inflow jet direction is influenced by external flow direction.

Fig. 12 shows a schematic representation of the effects of incoming wind angle on the CV flow: as the inflow jet deviates from the normal direction its effective inflow area is reduced, resulting in
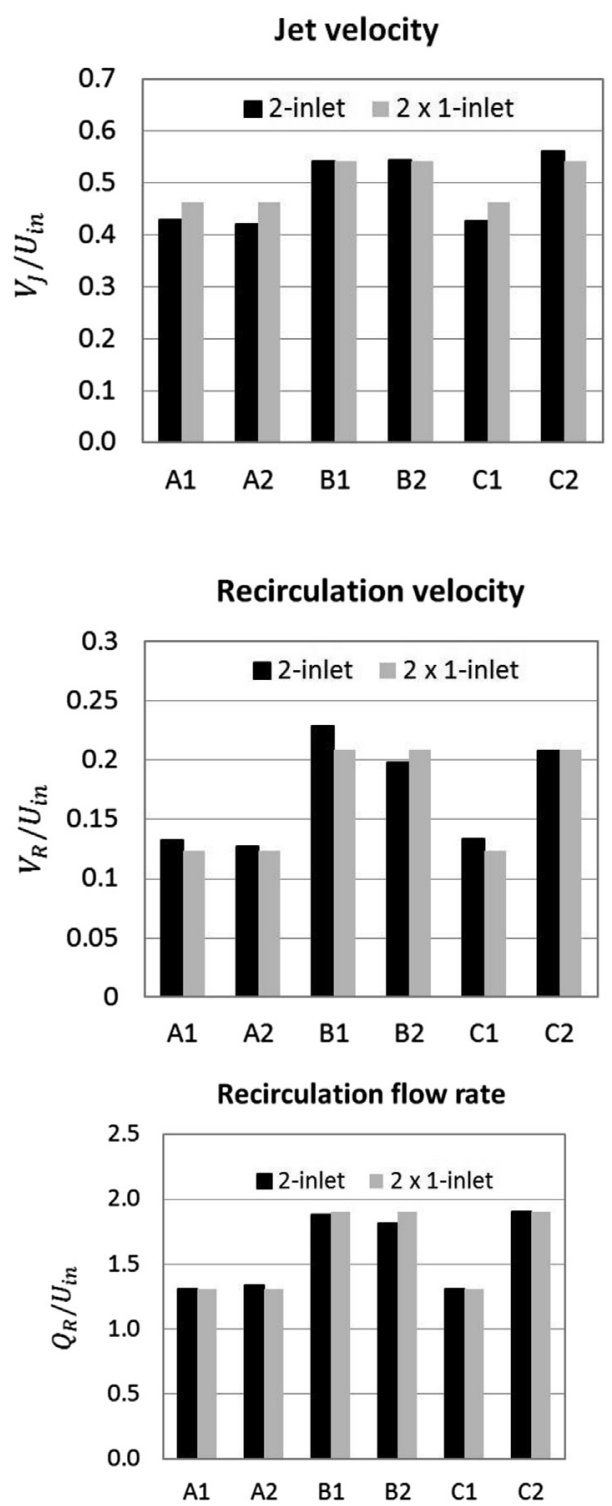

Fig. 11. Jet velocity, recirculation velocity and recirculation flow for the two halves of Cases A-C, compared with the corresponding 1-inlet spaces.

a larger velocity for the same flow rate. Because indoor velocities scale linearly with inflow velocity, this area reduction will have a relevant impact on the indoor velocity field. This oblique inflow geometry has two main effects on the flow and consequent correlation predictions: the inflow area is reduced, creating a larger inflow velocity for a given flow rate, and the flow path length is increased, resulting in a larger apparent room depth. The first effect increases indoor velocities while the second decreases the velocities. Quantitatively the effects can be modelled by two changes in flow geometry:

$A_{\text {in }, \varphi}=A_{\text {in }} \cos \varphi, D_{\varphi}=\frac{D}{\cos \varphi}$

The effect of the change in depth is limited by the possibility of the jet hitting and attaching to the room side walls; it is therefore difficult to quantify the exact variation in jet developing depth. The effect of the change in inflow area dominates that of the change in depth, although this may not be the case if the aperture depth (wall thickness) is comparable to the inlet characteristic diameter, as this 

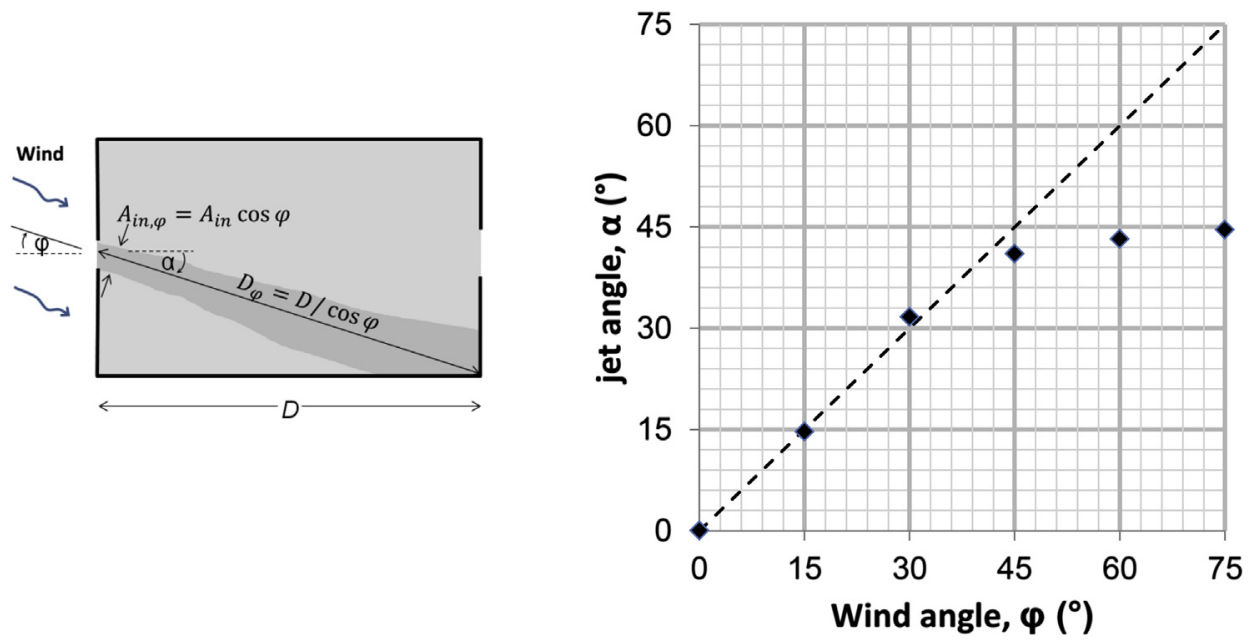

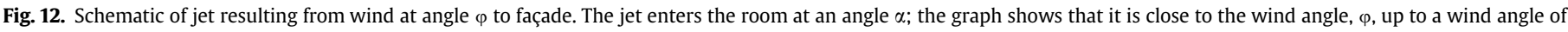
$45^{\circ}$, but then tends to level out to a constant value (dependent on the ratio of wall thickness to aperture size).

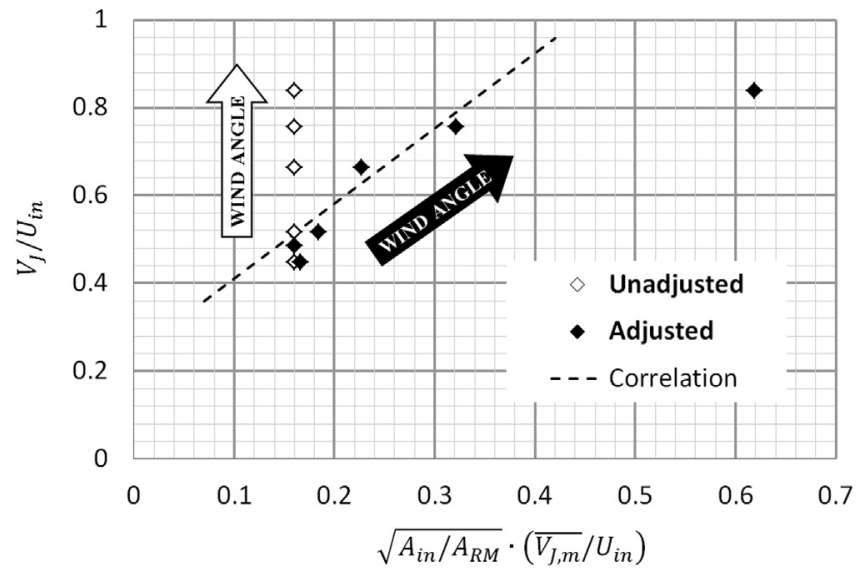

Fig. 13. Zero-wind-angle jet velocity correlation re-interpreted for non-zero wind angles.

will tend to align the inflow jet normal to the façade: in the present case, the ratio between the two was $\sim 0.1$, a typical ratio found in building ventilation. Clearly, as this ratio tends to 1 , the jet angle will tend to zero for all incoming wind angles.
From a practical point of view, the designer would like to use the zero-wind-angle correlation formulae, in conjunction with the standard external parameters of total inflow $Q_{\text {in }}$ and inlet area $A_{\mathrm{in}}$, for non-zero wind angles with minimal adjustment. For $\varphi>0$, the relevant jet driving velocity is no longer $U_{\text {in }}=\left(Q_{\text {in }} / A_{\text {in }}\right)$, but is instead the component in the jet direction, $U_{\mathrm{in}, \varphi}$, say, which is approximately $Q_{\text {in }} /\left(A_{\text {in }} \cos \varphi\right)$. Similarly, the relevant volumeaveraged jet velocity, $V_{\mathrm{J}, \varphi}$, is the average component along the jet. We can, therefore, correct for the wind angle to first order by including a factor of $1 /(\cos \varphi)$ in the $x$-coordinate of Fig. 8, while retaining the $y$-coordinate as $V_{\mathrm{J}, \varphi} / U_{\text {in }}$.

The effect of this adjustment factor is illustrated in Fig. 13. For the example of the $6 \mathrm{~m} \times 9 \mathrm{~m} \times 2.3 \mathrm{~m}$ room with $0.5 \mathrm{~m}^{2}$ inlet aperture, the normalized volume-averaged jet velocity (i.e. along the jet), $V_{\mathrm{J}, \varphi} / U_{\text {in }}$ was computed from CFD runs at wind angles of $15^{\circ}$, $30^{\circ}, 45^{\circ}, 60^{\circ}$ and $75^{\circ}$ and plotted against the unadjusted $x$-coordinate (open symbols) and the adjusted $x$-coordinate (solid symbols). The $y$-value increases with wind angle, since $Q_{\text {in }}$ decreases. The inclusion of the adjustment factor satisfactorily brings the cases with non-zero wind angle into line with the zero-wind-angle correlation curve. The mean error is $8 \%$ for the wind angles $0-60^{\circ}$, which lie within the range for the correlation dataset, but becomes unsuitable for larger wind angles. (a)

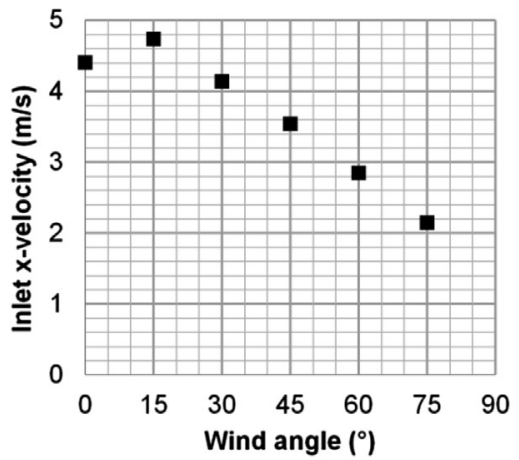

(b)

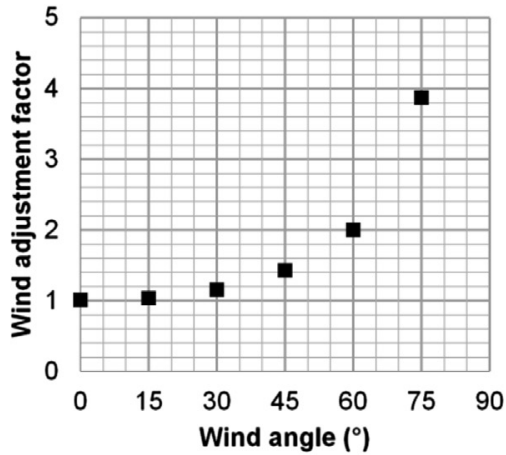

(c)

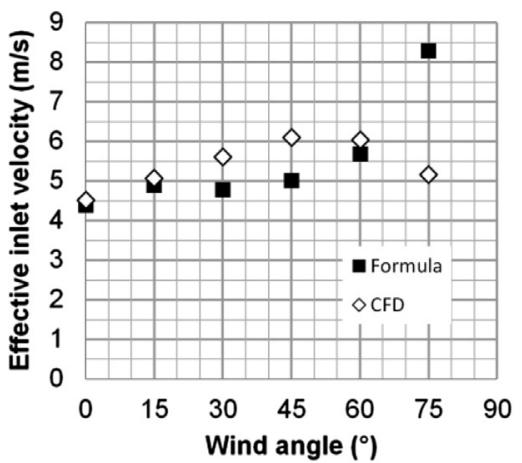

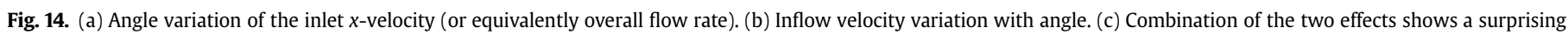
increase in inlet velocities up to $60^{\circ}$; solid symbols are values expected due to wind adjustment factor; open symbols are taken directly from simulation results. 
For a CV space in an isolated building, the combination of wind effects with jet inflow angle variation (and the consequent increase in flow driving velocity), results in an unexpected increase in indoor airflow velocity up to a $60^{\circ}$ departure from normal incidence. Fig. 14 shows the results of CFD runs for the above case with wind angles up to $60^{\circ}$. Fig. 14 (a) shows the variation of inflow $x$-velocity $U_{\text {in }}$ with wind angle, while (b) plots the wind angle adjustment factor $1 /(\cos \varphi)$. Fig. 14 (c) plots the effective inflow velocity, which is the product of the two, $U_{\text {in }} / \cos \varphi$, together with the average jet velocity magnitude at the inlet deduced from the CFD results. The net combined effect of the two mechanisms is a higher consistency for CV flows with variable wind angle: the increase in inflow velocity partially compensates the decrease in overall flow rate. Note that the simulations suggest there is additional enhancement of velocities over and above the geometric wind angle effect. Eventually, however, the jet flow will break down as the wind approaches a direction parallel to the façade, and the inlet velocity $U_{\text {in, } \varphi}$, will decrease; this, combined with the overall decrease in flow rate due to the falling pressure difference across the building, means that the driving jet velocity falls off rapidly as $\varphi$ approaches $90^{\circ}$.

\section{Conclusions}

Cross-ventilated room airflow depends on the ratio between inflow and room cross-sectional areas $A^{*}=A_{\mathrm{in}} / A_{\mathrm{RM}}$. When $A^{*}>0.5$ the flow resembles a unidirectional piston flow with no recirculation regions. This paper focuses on the more common and complex case of flow with recirculation regions that occurs when $A^{*}<0.5$. For this case, the results presented above confirm the possibility of characterizing the flow as a confined axisymmetric jet flow that drives the recirculation regions as lid-driven cavity flows.

The model correlation expressions predict the average indoor velocities in two distinct regions of the flow, the jet and recirculation regions, using a linear function of inflow velocity and two non-dimensional variables, namely $A^{*}$ and $D^{*}$ (the ratio of room depth to characteristic inflow diameter). For a given inflow velocity indoor velocities are proportional to $A^{* 1 / 2}$ and inversely proportional to $D^{*}$ : longer rooms have lower indoor velocities (due to increased jet decay), while spaces with a larger ratio of inflow to room cross-sectional area have higher velocities for the same inflow velocity. Maximum airflow rate in the recirculation region varies with $A_{\mathrm{RM}}^{1 / 2}$ : wider rooms have larger recirculation flow rates. For the typical inflow velocity and internal sensible heat gain density that occurs in CV buildings, buoyancy effects, outlet geometry and aperture shape factor do not have a significant impact on airflow velocities.

The results of this study also show that spaces with multiple inflow openings can be modelled as a set of single inflow opening rooms in parallel. In these cases, interference of the adjacent recirculating flows leads to negligible change in indoor velocities. For isolated CV spaces, variations in impinging flow direction change the inflow driving velocity in a way that compensates the decrease in static pressure that occurs for non-normal wind angles, making these CV flows partially self-regulating.

\section{Acknowledgements}

The work described in this paper was carried out under California Energy Commission contract 500-10-025, and their financial support is gratefully acknowledged. The authors would also like to thank Nuno Martins, Dave Banks, Philip Haves and António Vallêra.

\section{Nomenclature}

\author{
Abbreviations \\ CFD computational fluid dynamics \\ CV cross-ventilation \\ LDCF lid-driven cavity flow \\ RANS Reynolds-averaged Navier-Stokes
}

Symbols

a Slope of correlation line (-)

$A^{*} \quad$ Ratio of inlet area to room cross-sectional area, $A_{\text {in }} / A_{\mathrm{RM}}$ $(-)$

$A_{\text {in }} \quad$ Area of inlet $\left(\mathrm{m}^{2}\right)$

$\mathrm{A}_{\mathrm{in}, \varphi} \quad$ Effective inlet area, adjusted for wind angle $\varphi\left(\mathrm{m}^{2}\right)$

$A_{i n}^{(i)} \quad$ Area of inlet $i$ in multi-inlet configuration $\left(\mathrm{m}^{2}\right)$

$A_{\text {out }} \quad$ Area of outlet $\left(\mathrm{m}^{2}\right)$

$A_{\mathrm{RM}} \quad$ Cross-sectional area of room in vertical plane $=W \cdot H\left(\mathrm{~m}^{2}\right)$

$b \quad$ Intercept of correlation line $(-)$

B Buoyancy flux $\left(\mathrm{m}^{4} / \mathrm{s}^{3}\right)$

$c_{\mathrm{p}} \quad$ Specific heat capacity of air $(\mathrm{J} / \mathrm{kg} / \mathrm{K})$

$C_{\mathrm{d}} \quad$ Discharge coefficient (-)

$C_{\mathrm{n}} \quad$ Constant in expression of flow similarity (-)

$C_{\mathrm{QR}} \quad$ Correlation constant for recirculation flow rate (-)

$C_{\mathrm{V}, \mathrm{J}} \quad$ Correlation constant for jet velocity (-)

$C_{\mathrm{V}, \mathrm{R}} \quad$ Correlation constant for recirculation velocity (-)

D Room depth (m)

$D^{*} \quad$ Non-dimensional room depth $=D / A_{\text {in }}^{1 / 2}(-)$

$D_{\varphi} \quad$ Effective room depth, adjusted for wind angle $\varphi(\mathrm{m})$

$f \quad$ Functional dependence on non-dimensional variables $A^{*}$ and $D^{*}(-)$

F Function representing non-dimensional internal velocity field (-)

FT $\quad$ Flushing time $=V_{\mathrm{RM}} / Q_{\text {in }}(\mathrm{s})$

$H \quad$ Room height (m)

$M \quad$ Momentum flux $\left(\mathrm{m}^{4} / \mathrm{s}^{2}\right)$

$\Delta p \quad$ Pressure drop from windward to leeward side of building (Pa)

Q $\quad$ Flow rate $\left(\mathrm{m}^{3} / \mathrm{s}\right)$

$Q_{\text {in }} \quad$ Flow rate at inlet $\left(\mathrm{m}^{3} / \mathrm{s}\right)$

$Q_{\text {in }}^{(i)} \quad$ Flow rate at inlet $i$ in multi-inlet configuration $\left(\mathrm{m}^{3} / \mathrm{s}\right)$

$Q_{R} \quad$ Maximum flow rate in recirculation regions $\left(\mathrm{m}^{3} / \mathrm{s}\right)$

$r \quad$ Pearson product-moment correlation coefficient (-)

Re Reynolds number

$R i \quad$ Richardson number

$t \quad$ Time (s)

$t^{*} \quad$ Non-dimensional time, scaled with flushing time $=t / F T$ $(-)$

$u \quad x$-velocity at a point in the flow $(\mathrm{m} / \mathrm{s})$

$U_{\text {in }} \quad$ Average $x$-velocity at inlet $=Q_{\text {in }} / A_{\text {in }}(\mathrm{m} / \mathrm{s})$

$U_{\mathrm{in}, \varphi} \quad$ Average $x$-velocity at inlet adjusted for wind angle $(\mathrm{m} / \mathrm{s})$

$U_{i n}^{(i)} \quad$ Average $x$-velocity at inlet $i$ in multi-inlet configuration $(\mathrm{m} / \mathrm{s})$

$v \quad$ Velocity scale $(\mathrm{m} / \mathrm{s})$

$V_{\mathrm{J}} \quad$ Jet velocity averaged over volume of jet $(\mathrm{m} / \mathrm{s})$

$V_{\mathrm{J}, \mathrm{m}} \quad$ Maximum (centreline) velocity for axisymmetric free jet $(\mathrm{m} / \mathrm{s})$

$\overline{V_{J . m}} \quad$ Jet velocity scale, derived from average of $V_{\mathrm{J}, \mathrm{m}}$ over depth of room $(\mathrm{m} / \mathrm{s})$

$V_{\mathrm{J}, \varphi} \quad$ Jet velocity averaged over volume of jet, adjusted for wind angle $\varphi(\mathrm{m} / \mathrm{s})$

$V_{\mathrm{n}} \quad$ Generic velocity correlation $(\mathrm{m} / \mathrm{s})$

$V_{R} \quad$ Recirculation velocity averaged over plane of maximum flow rate $(\mathrm{m} / \mathrm{s})$ 
$V_{\mathrm{RM}} \quad$ Volume of room $\left(\mathrm{m}^{3}\right)$

$W \quad$ Room width (m)

$x \quad$ Coordinate along the room (m)

$x^{*} \quad$ Non-dimensional $x$-coordinate, scaled with characteristic inlet dimension $=x / A_{\text {in }}^{1 / 2}(-)$

$y \quad$ Horizontal coordinate across the room (m)

$z \quad$ Vertical coordinate $(\mathrm{m})$

Greek symbols

$\alpha \quad$ Angle between jet axis inside room and façade normal $\left(^{\circ}\right)$

$\rho \quad$ Density of air $\left(\mathrm{kg} / \mathrm{m}^{3}\right)$

$\varphi \quad$ Angle between approaching wind and façade normal $\left(^{\circ}\right)$

\section{References}

[1] Curtet R. Confined jets and recirculation phenomena with cold air. Combust Flame 1958;2(4):383-411.

[2] Becker HA, Hottel HC, Williams GC. Mixing and flow in ducted turbulent jets. Symposium Int Combust 1963:9(1):7-20.

[3] Maurel A, Ern P, Zielinska BJA, Wesfreid JE. Experimental study of selfsustained oscillations in a confined jet. Phys Rev E 1996;54(4):3643-51.

[4] Liu $\mathrm{H}$, Winoto $\mathrm{SH}$, Shah DA. Velocity measurements within confined turbulent jets: application to cardiovalvular regurgitation. Ann Biomed Eng 1997;25(6): 939-48.

[5] Karava P, Stathopoulos T, Athienitis AK. Airflow assessment in crossventilated buildings with operable façade elements. Build Environ January 2011;46(1):266-79. ISSN 0360-1323, http://dx.doi.org/10.1016/j.buildenv. 2010.07.022.

[6] Nikolopoulos Nikos, Nikolopoulos Aristeidis, Larsen Tine $S$ Nikas Konstantinos-Stefanos P. Experimental and numerical investigation of the tracer gas methodology in the case of a naturally cross-ventilated building. Build Environ October 2012;56:379-88. ISSN 0360-1323, http://dx.doi.org 10.1016/j.buildenv.2012.04.006.

[7] Carrilho da Graça G, Linden PF. Simplified modeling of cross-ventilation airflow. ASHRAE Trans 2003;109(1):4605-19.

[8] Carrilho da Graça G. Simplified models for heat transfer in rooms [Ph.D. dissertation]. San Diego: University of California; 2003 [Department of Mechanical and Aerospace Engineering].

[9] Zhai Zhiqiang (John), Johnson Mary-Hall, Krarti Moncef. Assessment of natura and hybrid ventilation models in whole-building energy simulations. Energy Build September 2011;43(9):2251-61. ISSN 0378-7788, http://dx.doi.org/10 1016/j.enbuild.2011.06.026.

[10] van Hooff T, Blocken B, Defraeye T, Carmeliet J, van Heijst GJF. PIV measurements and analysis of transitional flow in a reduced-scale model: ventilation by a free plane jet with Coanda effect. Build Environ October 2012;56:301-13. ISSN 0360-1323, http://dx.doi.org/10.1016/j.buildenv.2012.03.020.

[11] Ramponi R, Blocken B. CFD simulation of cross-ventilation for a generic isolated building: impact of computational parameters. Build Environ July 2012;53:34-48. ISSN 0360-1323, http://dx.doi.org/10.1016/j.buildenv.2012 01.004

[12] Bangalee MZI, Miau JJ, Lin SY, Yang JH. Flow visualization, PIV measurement and CFD calculation for fluid-driven natural cross-ventilation in a scale model Energy Build November 2013;66:306-14. ISSN 0378-7788, http://dx.doi.org/ 10.1016/j.enbuild.2013.07.005.

[13] Ji Liang, Tan Hongwei, Kato Shinsuke, Bu Zhen, Takahashi Takeo. Wind tunnel investigation on influence of fluctuating wind direction on cross natural ventilation. Build Environ December 2011;46(12):2490-9. ISSN 0360-1323, http://dx.doi.org/10.1016/j.buildenv.2011.06.006.
[14] James Lo L, Novoselac Atila. Cross ventilation with small openings: measurements in a multi-zone test building. Build Environ November 2012;57: 377-86. ISSN 0360-1323, http://dx.doi.org/10.1016/j.buildenv.2012.06.009.

[15] Aynsley, R. M., W. Melbourne, and B. J. Vickery. Architectural aerodynamics.

[16] Ernest D, Bauman Fred, Arens Edward A. The prediction of indoor air motion for occupant cooling in naturally ventilated buildings. ASHRAE Trans 1991;97.

[17] Givoni, B. Man, Climate and architecture, 2d Ed New York: Van Nostrand Reinhold.

[18] Chen Q. Comparison of different k- $\mathrm{k}$ models for indoor air flow computations. Numer Heat Transf Part B Fundam 1995;28(3):353-69.

[19] van Hooff T, Blocken B, van Heijst GJF. On the suitability of steady RANS CFD for forced mixing ventilation at transitional slot Reynolds numbers. Indoor Air 2013:23(3):236-49.

[20] Evola G, Popov V. Computational analysis of wind driven natural ventilation in buildings. Energy Build 2006;38(5):491-501.

[21] Stavrakakis GM, Koukou MK, Vrachopoulos MGr, Markatos NC. Natural crossventilation in buildings: building-scale experiments, numerical simulation and thermal comfort evaluation. Energy Build 2008;40(9):1666-81.

[22] Chu Chia-Ren, Chiang Bo-Fan. Wind-driven cross ventilation in long buildings. Build Environ October 2014;80:150-8. ISSN 0360-1323, http://dx.doi.org/10. 1016/j.buildenv.2014.05.017.

[23] Perén JI, van Hooff T, Leite BCC, Blocken B. CFD analysis of cross-ventilation of a generic isolated building with asymmetric opening positions: Impact of roof angle and opening location. Build Environ February 2015;85:263-76. ISSN 0360-1323, http://dx.doi.org/10.1016/j.buildenv.2014.12.007.

[24] Wu Yu-Chou, Yang An-Shik, Tseng Li-Yu, Liu Chin-Lung. Myth of ecological architecture designs: comparison between design concept and computational analysis results of natural-ventilation for Tjibaou Cultural Center in New Caledonia. Energy Build October 2011;43(10):2788-97. ISSN 0378-7788, http://dx.doi.org/10.1016/j.enbuild.2011.06.035.

[25] Lai JCS, Nasr A. Two parallel plane jets: comparison of the performance of three turbulence models. Proc Institution Mech Eng Part G J Aerosp Eng 1998;212(6):379-91.

[26] Karimpour A, Kaye NB, Khan AA. CFD study of merging turbulent plane jets. J Hydraul Eng 2011;137(3):381-5.

[27] Shankar PN, Deshpande MD. Fluid mechanics in the driven cavity. Ann Rev Fluid Mech 2000;32:93-136.

[28] Prasad AK, Koseff JR. Reynolds number and end-wall effects on a lid-driven cavity flow. Phys Fluids A 1989;1(2):208-18.

[29] Ricou FP, Spalding DB. Measurements of entrainment by axisymmetrical turbulent jets. J Fluid Mech 1961;11(1):21-32.

[30] White Frank M. Fluid mechanics, chapter 5. 7th ed. Boston: McGraw-Hill; 2011.

[31] Awbi Hazim B. Ventilation of buildings [Chapter 3]. Taylor \& Francis; 2003.

[32] Kandakure MT, Patkar VC, Patwardhan AW. Characteristics of turbulent confined jets. Chem Eng Process Process Intensif 2008;47(8):1234-45.

[33] Pani BS. Three dimensional turbulent wall jets [Ph.D. dissertation]. University of Alberta; 1972.

[34] Winoto SH, Shah DA, Ang SG, Chua LP. Prediction of orifice size from velocity measurements within the issuing free jets. In: White FM, Kamemoto K, editors. General topics in fluids engineering. New York: ASME; 1991. p. 47-51. FED-107.

[35] Franke J, Hellsten A, Schlünzen H, Carissimo B, editors. Best practice guideline for the CFD simulation of flows in the urban environment. Report produced by COST Action 732, Quality assurance and improvement of microscale meteorological models. 1 May 2007; 2007.

[36] Linden PF, et al. Natural ventilation for energy savings in California commercial buildings [California Energy Commission report (to appear)]. 2014.

[37] Nielsen PV. Specification of a two-dimensional test case. IEA-ECBCS Annex 20, Research Item No. 1.45. Institut for Bygningsteknik, Aalborg Universitetscenter; 1990.

[38] Carrilho da Graça G, Linden PF, Haves P. Design and testing of a control strategy for a large, naturally ventilated office building. Build Serv Eng Res Technol 2004;25(3):223-39. 